\title{
Do High Visibility Enforcement Programs Affect Aggressive Driving Behavior? An Empirical Analysis Using Naturalistic Driving Study Data
}

By

\section{Sarvani Sonduru Pantangi}

Graduate Research Assistant, Department of Civil, Structural and Environmental Engineering Engineering Statistics and Econometrics Application Research Laboratory University at Buffalo, The State University of New York

204B Ketter Hall, Buffalo, NY 14260; Phone: (716) 770-9380; Email: sarvanis@buffalo.edu

\section{Grigorios Fountas}

Lecturer

Transport Research Institute, School of Engineering and the Built Environment Edinburgh Napier University

10 Colinton Road, Edinburgh, EH10 5DT, UK; Phone: +44 131455 2711; Email:

G.Fountas@napier.ac.uk

Panagiotis Ch. Anastasopoulos (Corresponding author)

Assoc. Professor and Stephen E. Still Chair of Transportation Engineering

Department of Civil, Structural and Environmental Engineering

Stephen Still Institute for Sustainable Transportation and Logistics

University at Buffalo, The State University of New York

241 Ketter Hall, Buffalo, NY 14260; Phone: (716) 645-4362; Email: panastas@buffalo.edu

\section{John Pierowicz}

Senior Research Scientist, Public Safety \& Transportation Group, CUBRC 4455 Genesee St., Suite 106, Buffalo, NY 14225; Phone: (716) 204-5100; Email: pierowicz@cubrc.org

Kevin Majka

Senior Research Scientist, Public Safety \& Transportation Group, CUBRC 4455 Genesee St., Suite 106, Buffalo, NY 14225; Phone: (716) 204-5100; Email: majka@cubrc.org

And

\author{
Alan Blatt \\ Public Safety \& Transportation Group, CUBRC \\ 4455 Genesee St., Suite 106, Buffalo, NY 14225; Phone: (716) 204-5100; Email: \\ blatt@cubrc.org
}


1 ABSTRACT

2 This paper investigates the effect of High Visibility Enforcement (HVE) programs on different

3 types of aggressive driving behavior, namely, speeding, tailgating, unsafe lane changes and 'other'

4 aggressive driving behavior types (occurrence of not-yielding right-of-way and red light or stop

5 signs violations). For this purpose, the Second Strategic Highway Research Program (SHRP2)

6 Naturalistic Driving Study (NDS) data are used, which include forward-facing videos and time

7 series information with regard to trips conducted at or near the locations of HVE implementation.

8 To capture the intensity and duration of speeding and tailgating, scaled metrics are developed.

9 These metrics can capture varying levels of aggressive driving behavior enabling, thus, a direct

10 comparison of the various behavioral aspects over time and among different drivers. To identify

11 the effect of HVE and other trip, driver, vehicle or environmental factors on speeding and

12 tailgating, while accounting for possible interrelationship among the behavior-specific scaled

13 metrics, Seeming Unrelated Regression Equation (SURE) models were developed. To analyze the

14 likelihood of occurrence of unsafe lane changes and 'other' aggressive driving behavior types, a

15 grouped random parameters ordered probit model with heterogeneity in means and a correlated

16 grouped random parameters binary logit model were estimated, respectively. The results showed

17 that drivers' awareness of HVE implementation has the potential to decrease aggressive driving

18 behavior patterns, especially unsafe lane changes and 'other' aggressive driving behaviors.

20 Keywords: High-visibility enforcement; Speeding; Tailgating; Unsafe lane changes; Aggressive

21 Driving Behavior; Grouped random parameters. 


\section{INTRODUCTION}

Aggressive driving behavior has been recognized as one of the most significant risk factors affecting the occurrence of traffic accidents (NCHRP, 2003; Paleti et al, 2010; Tarko et al., 2011;

Sarwar and Anastasopoulos, 2016; Sarwar et al., 2017b). In fact, 27\% of traffic fatalities in 2015 involved at least one speeding driver along with other aggressive driving activities such as failure

to yield right-of-way (7\%) and unsafe lane changes (7.5\%) (Tasca, 2000; National Center for Statistics and Analysis, 2017).

Aggressive driving behavior, which increases the accident risk for drivers and other road users, may be caused by the individual or combined effect of various causal factors (Tasca, 2000; Stuster, 2004; Shinar and Compton, 2004; Simons-Morton et al, 2011; Tarko et al.,2011). Various studies have been carried out to understand the nuances of aggressive driving behavior and associated causal factors. Causal factors of aggressive driving behavior have been classified into three broad categories: situational and environmental conditions, demographic characteristics of the drivers, and disposition of the driver (Tasca, 2000; Ellison-Potter et al., 2001; Shinar and Compton, 2004). Over the last few years, various analytic, data-intensive approaches have been used to identify aggressive driving and its impact on road safety including driving simulation approaches (Ellison-Potter et al., 2001; Sarwar et al., 2017b; Fountas et al., 2019; Meng et al., 2019), traffic simulation approaches (Habtemichael and de Picado Santos, 2014; Yang et al., 2018) and, more recently, use of naturalistic driving study data (Fang et al., 2017; Sarwar et al., 2017a; Sarwar et al., 2017c; Wang et al., 2019; Pantangi et al., 2019).

The High Visibility Enforcement (HVE) programs constitute a collection of enforcement measures introduced to tackle aggressive driving behavior. To evaluate the effectiveness of these programs in terms of reducing aggressive driving incidents, previous studies have employed 
1 various criteria, such as: comparison of number of traffic citations before and after the enforcement

2 period; number of crashes before, during and after the enforcement period; number of crashes at

3 the enforcement site versus number of crashes at an appropriately selected control site; self-

4 reporting surveys of driving behavior; road side compliance studies and so on. Due to their

5 aggregate nature, the aforementioned measures cannot provide direct information for significant

6 aspects of driving behavior, such as the driver's interaction with the traffic stream, traffic control

7 or roadway infrastructure or the internal and external distractions, to name a few (Stuster, 2004;

8 Tarko et al., 2011; Cunningham et al., 2011; Wu and Jovanis, 2012; Files, 2013).

$9 \quad$ This paper aims at investigating whether the high visibility enforcement programs address

10 aggressive driving behavior and which aggressive driving patterns are primarily affected. In this

11 context, the effect of various driver-, vehicle-, or trip-specific characteristics that may also affect

12 driving behavior is controlled for. Using the Second Strategic Highway Research Program

13 (SHRP2) Naturalistic Driving Study (NDS) data, the following aggressive driving behaviors are

14 statistically analyzed: speeding, tailgating, unsafe lane changes and 'other' aggressive driving

15 behavior types (including red light/ stop sign violation and not-yielding right-of-way) (Wu and

16 Jovanis, 2012; Files, 2013). Even though the recent study of Pantangi et al. (2019) provided a

17 preliminary investigation of the HVE effectiveness using novel speeding and tailgating metrics,

18 this study goes a step beyond by developing scaled metrics that combine the intensity and duration

19 of speeding and tailgating and capture varying degrees of aggressive driving behavior at a more

20 disaggregate level. To account for the potential interrelationship of speeding and tailgating, the

21 relevant metrics are simultaneously modeled using a Seemingly Unrelated Regression Equation

22 (SURE) approach. To investigate the factors affecting the occurrence of unsafe lane changes, the

23 grouped random parameters ordered probit framework with heterogeneity in the means is 
1 employed, whereas the occurrence of “other” aggressive driving behavior types is modeled using

2 a correlated grouped random parameters binary logit approach. Through these modeling

3 approaches, various nuances of unobserved heterogeneity that may be present in the statistical

4 analysis of highly disaggregate data (such as the naturalistic driving study data) can be adequately

5 addressed.

6

7 EMPIRICAL SETTING

8 The SHRP2 NDS data allows for studying a wide variety of driving behavior traits, as they include

9 information for a number of driver, trip, vehicle, and roadway environment characteristics (Jovanis

10 et al., 2011; Wu and Jovanis, 2012; Feng et al., 2017; Lee et al., 2018; Wang et al., 2018). For this

11 study, two HVE programs conducted during the SHRP2 NDS data collection period (October 2010

12 to November 2013) in Erie County, NY, were selected with the help of the local police departments

13 (Pierowicz et al., 2016; Sarwar et al., 2017a; Pantangi et al., 2019). The first HVE program was

14 conducted intermittently by the police department of Amherst, NY, between March and September

15 2012, along Millersport Highway in Amherst, NY. The enforcement activities were mostly

16 concentrated during May. The second HVE program was conducted by the police department of

17 Depew, NY in May 2012 along Transit road in Depew, NY. The enforcement activities were

18 conducted on weekdays primarily between 6:00 AM and 9:00 PM. The program in Depew, NY

19 was concentrated near a school zone, so the test and control sites were appropriately selected to

20 include school speed limits. In both programs aggressive driving behavior was addressed using

21 both roving car patrols and fixed car patrols in the test areas during the enforcement period. To

22 raise the awareness of local residents about the HVE programs during the enforcement period, a

23 media campaign was undertaken. This campaign comprised of announcements in local newspapers

24 (Amherst Bee and Depew Bee) along with public radio announcements and roadside messages (in 
1 Amherst). To identify possible changes in driving behavior between enforcement and non-

2 enforcement sites, control (non-enforcement) sites with similar roadway and speed limit

3 characteristics to the test sites were selected near the enforcement areas. Figure 1 illustrates the

4 location of the test and control sites.

6

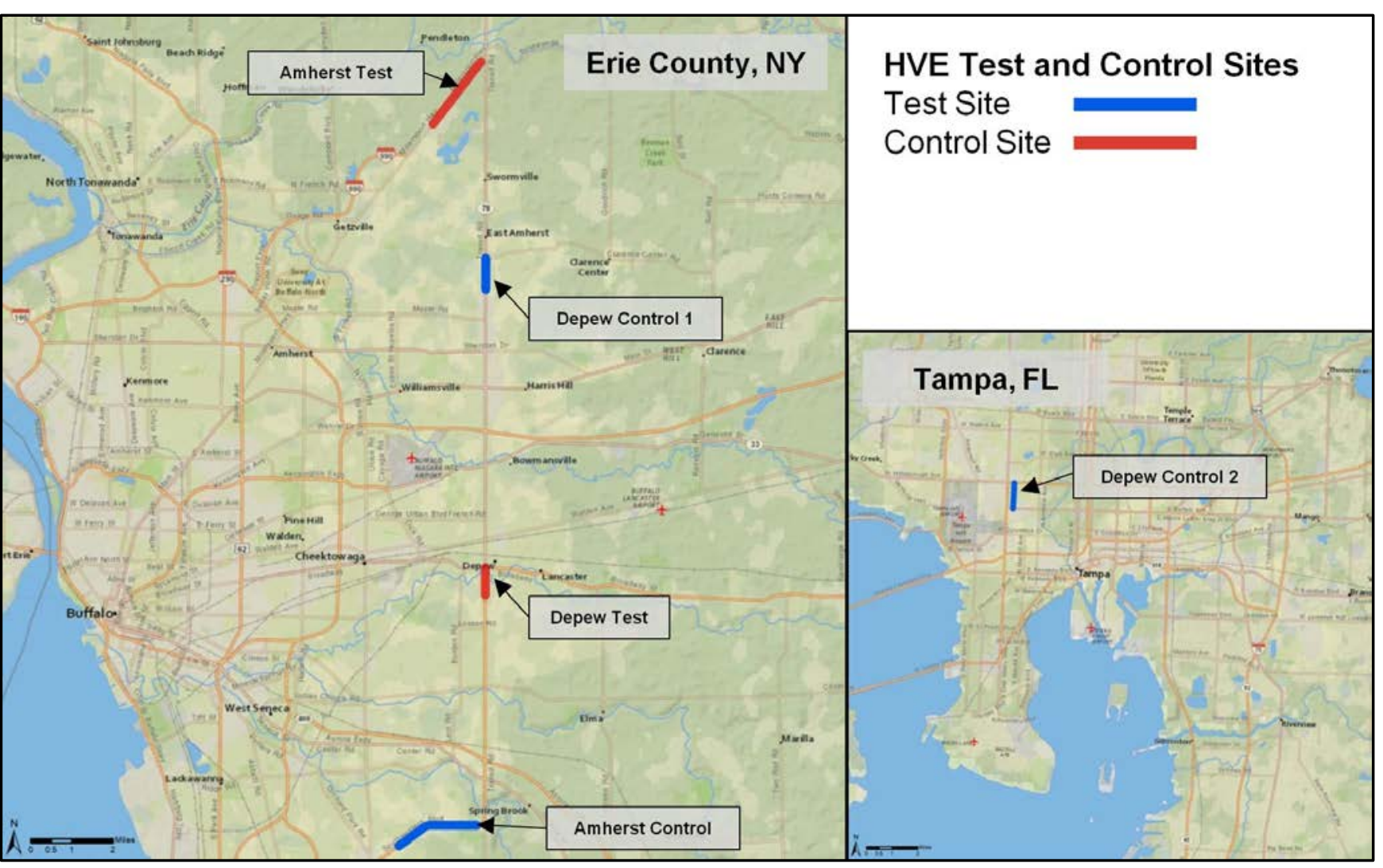

Figure 1. High-Visibility Enforcement (HVE) and Control Sites Included in the Analysis.

The analysis presented in this paper is based on extensive data from 1,758 traversals, conducted by 141 participants in enforcement and non-enforcement sites, and on a set of relevant driver-, vehicle- and trip- characteristics. Of these traversals, 408 were conducted in the Depew enforcement area and 337 in the Amherst enforcement area, with 433 and 454 trips being conducted in the corresponding control areas. Moreover, data from 126 trips conducted in a remote 
1 area in Tampa, FL were also used; this area served as an additional control area for the Depew

2 enforcement area.

3 The selection of traversals was based on multiple criteria such as temporal characteristics of 4 traversals, vehicle characteristics, and participants' demographics. Apart from the key 5 demographic attributes (e.g., age, gender), information about the household characteristics of each 6 participant (e.g., number of people living in the participant's household along with their 7 demographic characteristics, number of household-owned vehicles) were also used in the analysis 8 of aggressive driving behavior. Information about participant's vehicular use (e.g., number of 9 miles driven in the previous year, length of vehicle ownership, and years of driving experience) 10 was also available in the participant-specific data. To capture participants' perceptual attitudes 11 towards various sources of accident risk, the responses of participants to a survey focusing on the 12 assessment of risk perceptions were also obtained from the SHRP2 dataset (Files, 2013). In 13 addition, the participants' responses to the Barkley’s ADHD (Attention Deficit Hyperactivity 14 Disorder) screening test were also used. Table 1 provides the descriptive statistics of the key 15 variables that are included in the statistical models of aggressive driving behavior. 
1 Table 1. Descriptive Statistics of Key Variables.

\begin{tabular}{|c|c|c|c|c|}
\hline Variable & Mean & Std. Dev. & Minimum & Maximum \\
\hline \multicolumn{5}{|l|}{ Speed Metric Model } \\
\hline $\begin{array}{l}\text { Speed metric (between speed limit and } 5 \text { mph above } \\
\text { speed limit) }\end{array}$ & 0.048 & 0.045 & 0 & 0.310 \\
\hline $\begin{array}{l}\text { Speed metric (between } 5 \text { and } 10 \mathrm{mph} \text { above speed } \\
\text { limit) }\end{array}$ & 0.016 & 0.029 & 0 & 0.405 \\
\hline $\begin{array}{l}\text { Speed metric (between } 10 \text { and } 15 \text { mph above speed } \\
\text { limit) }\end{array}$ & 0.004 & 0.012 & 0 & 0.125 \\
\hline Speed metric (greater than 15 mph above speed limit) & 0.004 & 0.031 & 0 & 0.526 \\
\hline $\begin{array}{l}\text { Age indicator ( } 1 \text { if the participant's age is less than } 35 \\
\text { years, } 0 \text { otherwise) }\end{array}$ & 0.411 & 0.492 & 0 & 1 \\
\hline $\begin{array}{l}\text { Work status indicator ( } 1 \text { if the participant does not } \\
\text { work full time, } 0 \text { otherwise) }\end{array}$ & 0.507 & 0.500 & 0 & 1 \\
\hline \multicolumn{5}{|l|}{ Household/Education indicator ( 1 if the participant } \\
\hline $\begin{array}{l}\text { lives in one-parent household or alone and has } \\
\text { some high school education, } 0 \text { otherwise) }\end{array}$ & 0.617 & 0.486 & 0 & 1 \\
\hline Number of vehicles in household & 2.299 & 1.095 & 1 & 5 \\
\hline $\begin{array}{l}\text { Trip area/Month indicator ( } 1 \text { if trip made in control } \\
\text { area in the month of May, } 0 \text { otherwise) }\end{array}$ & 0.268 & 0.443 & 0 & 1 \\
\hline $\begin{array}{l}\text { Income indicator ( } 1 \text { if the household income is } \\
\text { between } \$ 40,000 \text { and } \$ 99,999,0 \text { otherwise) }\end{array}$ & 0.408 & 0.492 & 0 & 1 \\
\hline $\begin{array}{l}\text { Age indicator ( } 1 \text { if the participant's age is between } 35 \\
\text { and } 49 \text { years, } 0 \text { otherwise) }\end{array}$ & 0.197 & 0.398 & 0 & 1 \\
\hline $\begin{array}{l}\text { ADHD indicator (1 if Barkley's score is less than 7, } 0 \\
\text { otherwise) }\end{array}$ & 0.026 & 0.158 & 0 & 1 \\
\hline $\begin{array}{l}\text { Vehicle type indicator ( } 1 \text { if the participant drove a car } \\
\text { or an SUV crossover, } 0 \text { otherwise) }\end{array}$ & 0.920 & 0.271 & 0 & 1 \\
\hline $\begin{array}{l}\text { Risk perception indicator(1 if the participant doesn't } \\
\text { perceive great risk in trying to be first off the line } \\
\text { when light turns green, driving } 10-20 \mathrm{mph} \text { above } \\
\text { speed limit or driving more than } 20 \mathrm{mph} \text { over speed } \\
\text { limit, } 0 \text { otherwise) }\end{array}$ & 0.904 & 0.295 & 0 & 1 \\
\hline $\begin{array}{l}\text { Trip frequency indicator ( } 1 \text { if the participant } \\
\text { undertook less than } 10 \text { trips, } 0 \text { otherwise })\end{array}$ & 0.217 & 0.413 & 0 & 1 \\
\hline $\begin{array}{l}\text { Risk perception indicator( } 1 \text { if participant doesn't } \\
\text { perceive great risk in making illegal turns, } 0 \\
\text { otherwise) }\end{array}$ & 0.356 & 0.479 & 0 & 1 \\
\hline Square of average trip speed $\left(\mathrm{mph}^{2}\right)$ & 1744.190 & 1124.347 & 31.035 & 7123.759 \\
\hline Average trip speed (mph) & 39.279 & 14.194 & 5.571 & 84.402 \\
\hline Trip Duration (secs) & 124.493 & 60.961 & 39.900 & 1051.900 \\
\hline \multicolumn{5}{|l|}{ Race indicator ( 1 if the participant is American } \\
\hline $\begin{array}{l}\text { Indian, Alaskan Indian, Asian or African } \\
\text { American, } 0 \text { otherwise) }\end{array}$ & 0.073 & 0.260 & 0 & 1 \\
\hline $\begin{array}{l}\text { Risk perception indicator ( } 1 \text { if the participant doesn't } \\
\text { perceive great risk in drinking alcohol or using } \\
\text { recreational drugs while driving, } 0 \text { otherwise) }\end{array}$ & 0.046 & 0.208 & 0 & 1 \\
\hline $\begin{array}{l}\text { Driver training indicator ( } 1 \text { if the participant was } \\
\text { trained informally by parents, a family friend, or a } \\
\text { personal friend, } 0 \text { otherwise) }\end{array}$ & 0.788 & 0.409 & 0 & 1 \\
\hline
\end{tabular}




\begin{tabular}{|c|c|c|c|c|}
\hline Variable & Mean & Std. Dev. & Minimum & Maximum \\
\hline $\begin{array}{l}\text { Risk perception indicator (1 if the participant doesn't } \\
\text { perceive great risk in driving to reduce tension, } 0 \\
\text { otherwise) }\end{array}$ & 0.280 & 0.449 & 0 & 1 \\
\hline $\begin{array}{l}\text { Risk perception indicator ( } 1 \text { if the participant doesn't } \\
\text { perceive immense risk in performing other things } \\
\text { while driving, like cell-phone usage, eating or } \\
\text { drinking etc., } 0 \text { otherwise) }\end{array}$ & 0.422 & 0.494 & 0 & 1 \\
\hline Vehicle age (years) & 4.577 & 2.664 & 1 & 14 \\
\hline $\begin{array}{l}\text { Time at residence indicator ( } 1 \text { if the participant lived } \\
\text { at residence for more than } 5 \text { years, } 0 \text { otherwise) }\end{array}$ & 0.632 & 0.482 & 0 & 1 \\
\hline $\begin{array}{l}\text { Driver Miles/Accidents/Violations indicator ( } 1 \text { if the } \\
\text { participant drove more than } 15,000 \text { miles in the } \\
\text { previous year and has had at-least one accident or } \\
\text { violation in the lifetime, } 0 \text { otherwise) }\end{array}$ & 0.477 & 0.500 & 0 & 1 \\
\hline $\begin{array}{l}\text { Risk perception indicator ( } 1 \text { if participant doesn't } \\
\text { perceive immense risk in driving while sleepy and } \\
\text { when hard to keep eyes open, } 0 \text { otherwise) }\end{array}$ & 0.437 & 0.496 & 0 & 1 \\
\hline $\begin{array}{l}\text { Vehicle use indicator ( } 1 \text { if the vehicle was used for } \\
\text { business purpose, } 0 \text { otherwise) }\end{array}$ & 0.087 & 0.282 & 0 & 1 \\
\hline $\begin{array}{l}\text { Risk perception indicator( } 1 \text { if participant doesn't } \\
\text { perceive any great risk with cutting off, honking or } \\
\text { yelling at other drivers who drive slowly or cut the } \\
\text { participant off , } 0 \text { otherwise) }\end{array}$ & 0.560 & 0.497 & 0 & 1 \\
\hline $\begin{array}{l}\text { Risk perception indicator ( } 1 \text { if the participant doesn't } \\
\text { perceive great risk in drinking alcohol or using } \\
\text { recreational drugs while or before driving, } 0 \\
\text { otherwise) }\end{array}$ & 0.151 & 0.358 & 0 & 1 \\
\hline $\begin{array}{l}\text { Driver training indicator ( } 1 \text { if the participant had } \\
\text { post-licensure driving skills training or } \\
\text { enhancement, } 0 \text { otherwise) }\end{array}$ & 0.125 & 0.331 & 0 & 1 \\
\hline $\begin{array}{l}\text { Average speeding (the vehicle speed is greater than } \\
\text { the speed limit) }\end{array}$ & 2.510 & 3.477 & 0 & 47.148 \\
\hline $\begin{array}{l}\text { Driver Miles indicator ( } 1 \text { if the participant drove less } \\
\text { than } 25,000 \text { miles in the previous year, } 0 \text { otherwise) }\end{array}$ & 0.830 & 0.376 & 0 & 1 \\
\hline $\begin{array}{l}\text { Risk perception indicator ( } 1 \text { if the participant doesn't } \\
\text { perceive great risk in driving more than } 20 \mathrm{mph} \\
\text { over the speed limit, } 0 \text { otherwise) }\end{array}$ & 0.157 & 0.364 & 0 & 1 \\
\hline $\begin{array}{l}\text { Income indicator ( } 1 \text { if household income of the } \\
\text { participant is greater than } \$ 100,000,0 \text { otherwise) }\end{array}$ & 0.280 & 0.449 & 0 & 1 \\
\hline $\begin{array}{l}\text { Work status/Gender indicator ( } 1 \text { if the participant is } \\
\text { female and does not work full time, } 0 \text { otherwise) }\end{array}$ & 0.751 & 0.432 & 0 & 1 \\
\hline $\begin{array}{l}\text { Vehicle age indicator ( } 1 \text { if the vehicle is older than } 5 \\
\text { years, } 0 \text { otherwise) }\end{array}$ & 0.254 & 0.435 & 0 & 1 \\
\hline $\begin{array}{l}\text { Attitude/Crash record indicator ( } 1 \text { if the respondent } \\
\text { doesn't perceive risk in driving while sleepy or } \\
\text { driving for fun and if the respondent had at-least } \\
\text { one crash or violation in the lifetime, } 0 \text { otherwise) }\end{array}$ & 0.664 & 0.473 & 0 & 1 \\
\hline $\begin{array}{l}\text { Gender indicator (1 if female participant, } 0 \\
\text { otherwise) }\end{array}$ & 0.522 & 0.500 & 0 & 1 \\
\hline
\end{tabular}




\begin{tabular}{|c|c|c|c|c|}
\hline Variable & Mean & Std. Dev. & Minimum & Maximum \\
\hline $\begin{array}{l}\text { Race/Area indicator ( } 1 \text { if the trip was undertaken by } \\
\text { a white participant in an area where the HVE } \\
\text { program was implemented, } 0 \text { otherwise) }\end{array}$ & 0.407 & 0.491 & 0 & 1 \\
\hline $\begin{array}{l}\text { Risk perception indicator ( } 1 \text { if the participant doesn't } \\
\text { perceive great risk in driving to reduce tension, } 0 \\
\text { otherwise) }\end{array}$ & 0.718 & 0.450 & 0 & 1 \\
\hline \multicolumn{5}{|l|}{ Tailgating Metric Model } \\
\hline $\begin{array}{l}\text { Tailgating metric (Following headway between } 2 \mathrm{~s} \\
\text { and } 1.5 \mathrm{~s} \text { ) }\end{array}$ & -3.539 & 7.949 & -59.508 & 0 \\
\hline $\begin{array}{l}\text { Tailgating metric (Following headway between } 1.5 \mathrm{~s} \\
\text { and } 1 \mathrm{~s} \text { ) }\end{array}$ & -1.869 & 5.332 & -49.641 & 0 \\
\hline Tailgating metric (Following headway less than 1 s) & -0.513 & 2.405 & -39.425 & 0 \\
\hline $\begin{array}{l}\text { Age indicator ( } 1 \text { if the participant's age is less than } 35 \\
\text { years, } 0 \text { otherwise) }\end{array}$ & 0.411 & 0.492 & 0 & 1 \\
\hline $\begin{array}{l}\text { Trip area/Month indicator ( } 1 \text { if the trip was made in } \\
\text { control area in the month of May, } 0 \text { otherwise) }\end{array}$ & 0.268 & 0.443 & 0 & 1 \\
\hline $\begin{array}{l}\text { Age indicator ( } 1 \text { if the participant's age is between } 35 \\
\text { and } 49 \text { years, } 0 \text { otherwise) }\end{array}$ & 0.197 & 0.398 & 0 & 1 \\
\hline Trip Duration (secs) & 124.372 & 61.087 & 0 & 1051.900 \\
\hline $\begin{array}{l}\text { Race indicator ( } 1 \text { if the participant is American } \\
\text { Indian, Alaskan Indian, Asian or African } \\
\text { American, } 0 \text { otherwise) }\end{array}$ & 0.073 & 0.260 & 0 & 1 \\
\hline $\begin{array}{l}\text { Driver training indicator ( } 1 \text { if the participant was } \\
\text { trained informally by parents, a family friend or a } \\
\text { personal friend, } 0 \text { otherwise) }\end{array}$ & 0.788 & 0.409 & 0 & 1 \\
\hline $\begin{array}{l}\text { Risk perception indicator ( } 1 \text { if the participant doesn't } \\
\text { perceive great risk in making illegal turns, } 0 \\
\text { otherwise) }\end{array}$ & 0.356 & 0.479 & 0 & 1 \\
\hline $\begin{array}{l}\text { Household/Education indicator ( } 1 \text { if participant lives } \\
\text { in one-parent household or alone and has some } \\
\text { high school education, } 0 \text { otherwise) }\end{array}$ & 0.617 & 0.486 & 0 & 1 \\
\hline Average trip speed (mph) & 39.254 & 14.231 & 2.296 & 84.402 \\
\hline $\begin{array}{l}\text { Driver Miles indicator ( } 1 \text { if the participant drove } \\
\text { more than } 15,000 \text { miles in the previous year, } 0 \\
\text { otherwise) }\end{array}$ & 0.223 & 0.417 & 0 & 1 \\
\hline $\begin{array}{l}\text { Time of trip indicator ( } 1 \text { if the trip was made between } \\
6 \text { am and noon or between } 3 \mathrm{pm} \text { and } 9 \mathrm{pm}, 0 \\
\text { otherwise) }\end{array}$ & 0.808 & 0.394 & 0 & 1 \\
\hline Number of traffic signals in a trip & 0.374 & 0.683 & 0 & 2 \\
\hline Square of average trip speed $\left(\mathrm{mph}^{2}\right)$ & 1743.270 & 1125.254 & 5.273 & 7123.759 \\
\hline Vehicle age (years) & 4.577 & 2.664 & 1 & 14 \\
\hline $\begin{array}{l}\text { Risk perception indicator ( } 1 \text { if the participant doesn't } \\
\text { perceive great risk in driving to reduce tension, } 0 \\
\text { otherwise) }\end{array}$ & 0.640 & 0.480 & 0 & 1 \\
\hline $\begin{array}{l}\text { Risk perception indicator ( } 1 \text { if the participant doesn't } \\
\text { perceive great risk in driving more than } 20 \mathrm{mph} \\
\text { over the speed limit, } 0 \text { otherwise) }\end{array}$ & 0.157 & 0.364 & 0 & 1 \\
\hline
\end{tabular}




\begin{tabular}{|c|c|c|c|c|}
\hline Variable & Mean & Std. Dev. & Minimum & Maximum \\
\hline $\begin{array}{l}\text { Education level indicator ( } 1 \text { if the participant had } \\
\text { some post-graduate education or has an advanced } \\
\text { degree, } 0 \text { otherwise) }\end{array}$ & 0.358 & 0.480 & 0 & 1 \\
\hline $\begin{array}{l}\text { Participant age indicator ( } 1 \text { if the participant was } \\
\text { older than } 65 \text { years, } 0 \text { otherwise) }\end{array}$ & 0.323 & 0.468 & 0 & 1 \\
\hline $\begin{array}{l}\text { Average speeding (the vehicle speed is greater than } \\
\text { the speed limit) }\end{array}$ & 2.507 & 3.475 & 0 & 47.148 \\
\hline $\begin{array}{l}\text { Trip frequency indicator ( } 1 \text { if the participant } \\
\text { undertook more than } 5 \text { trips, } 0 \text { otherwise) }\end{array}$ & 0.997 & 0.058 & 0 & 1 \\
\hline \multicolumn{5}{|l|}{ Unsafe lane changes model } \\
\hline Frequency of unsafe lane changes & 0.337 & 0.638 & 0 & 3 \\
\hline $\begin{array}{l}\text { HVE/Month Indicator ( } 1 \text { if trip made in HVE area in } \\
\text { May, June or July,0 otherwise) }\end{array}$ & 0.197 & 0.398 & 0 & 1 \\
\hline $\begin{array}{l}\text { Time at residence indicator ( } 1 \text { if the participant lived } \\
\text { at the residence for more than } 5 \text { years, } 0 \text { otherwise) }\end{array}$ & 0.632 & 0.482 & 0 & 1 \\
\hline $\begin{array}{l}\text { Vehicle age indicator ( } 1 \text { if the vehicle was older than } \\
5 \text { years, } 0 \text { otherwise) }\end{array}$ & 0.371 & 0.483 & 0 & 1 \\
\hline $\begin{array}{l}\text { Vehicle/ Household size indicator ( } 1 \text { if household } \\
\text { size }>2 \text { and number of vehicles owned }>2,0 \\
\text { otherwise) }\end{array}$ & 0.254 & 0.435 & 0 & 1 \\
\hline $\begin{array}{l}\text { Driver training indicator ( } 1 \text { if the participant was } \\
\text { trained informally by parent, family friend or } \\
\text { friend, } 0 \text { otherwise) }\end{array}$ & 0.735 & 0.441 & 0 & 1 \\
\hline $\begin{array}{l}\text { Crashes/Violations indicator ( } 1 \text { if driver had at least } \\
1 \text { crash or violation, } 0 \text { otherwise) }\end{array}$ & 0.507 & 0.500 & 0 & 1 \\
\hline $\begin{array}{l}\text { Vehicle classification indicator ( } 1 \text { if the vehicle } \\
\text { driven is car or pickup truck, } 0 \text { otherwise) }\end{array}$ & 0.788 & 0.409 & 0 & 1 \\
\hline \multicolumn{5}{|l|}{ ‘Other’ Aggressive Driving Behaviors Model } \\
\hline Occurrence of 'other' aggressive driving behaviors & 0.043 & 0.204 & 0 & 1 \\
\hline $\begin{array}{l}\text { Month/HVE indicator (1 if trip made after 6th May } \\
2012 \text { in HVE implementation area, } 0 \text { otherwise) }\end{array}$ & 0.057 & 0.232 & 0 & 1 \\
\hline $\begin{array}{l}\text { Gender/work status indicator ( } 1 \text { if female respondent } \\
\text { without full time employment, } 0 \text { otherwise) }\end{array}$ & 0.751 & 0.432 & 0 & 1 \\
\hline $\begin{array}{l}\text { Vehicle classification indicator ( } 1 \text { if the vehicle } \\
\text { driven is car or pickup truck, } 0 \text { otherwise) }\end{array}$ & 0.735 & 0.441 & 0 & 1 \\
\hline $\begin{array}{l}\text { Attitude/Crash record indicator (1 if respondent } \\
\text { doesn't perceive risk in making illegal turns and if } \\
\text { the respondent had at least one crash or violation in } \\
\text { their lifetime, } 0 \text { otherwise) }\end{array}$ & 0.692 & 0.462 & 0 & 1 \\
\hline $\begin{array}{l}\text { Household size indicator ( } 1 \text { if number of people in } \\
\text { household is greater than 2, } 0 \text { otherwise) }\end{array}$ & 0.502 & 0.500 & 0 & 1 \\
\hline $\begin{array}{l}\text { Ethnicity indicator ( } 1 \text { if the participant has Hispanic } \\
\text { or Latino ethnicity) }\end{array}$ & 0.047 & 0.211 & 0 & 1 \\
\hline $\begin{array}{l}\text { Average speeding (the vehicle speed is greater than } \\
\text { the speed limit) }\end{array}$ & 2.510 & 3.477 & 0 & 47.148 \\
\hline
\end{tabular}




\section{METHODOLOGICAL APPROACH}

To understand the effect of HVE programs in modifying aggressive driving behavior, forward facing camera videos and time series data were both leveraged in identifying and quantifying various types of aggressive driving behavior.

Speeding has been defined as exceeding the posted speed limit or driving too fast for the prevailing environmental conditions (Bagdade et al., 2012). To further capture differences arising either from the extent or the duration of speeding behavior, four speed thresholds are considered: speed limit and 5, 10, and $15 \mathrm{mph}$ above the posted speed limit, thus, scaled speeding metrics are developed. Such metrics are calculated as the area between the vehicle network speed and the speed threshold, in cases where the vehicle speed is greater than the specific speed threshold. These metrics enable the comparison of speeding behavior and its changes over time while accounting, at the same time, for intensity of speeding (i.e., speeding above a pre-defined threshold during the trip) and the duration of speeding (i.e., length of time during which speeding above a pre-defined threshold was observed). Their scaled nature also allows the identification of speeding patterns for drivers with varying levels of risk-taking behavior.

In this context, four scaled speed metrics and an overall speed metric are calculated for Amherst and Depew test and control areas, as illustrated in Figure 2. Four shaded areas are illustrated in Figure 2, with the first (green shaded area) representing the extent and duration of speeding between the speed limit and $5 \mathrm{mi} / \mathrm{h}$ over the speed limit. The second (yellow shaded), third (blue shaded), and fourth (red shaded) areas represent the extent and duration of speeding between 5 and 10, 10 and 15, and 15 or more mi/h over the speed limit.

Each speed metric has been calculated as the area between the threshold and the network speed averaged over the length of the trip, as shown in Equation 1 (Pantangi et al., 2019): 
1 Speed metric $\mathrm{m}_{\mathrm{m}, \mathrm{j}}=\frac{\left[\sum_{\mathrm{k}=1}^{\mathrm{n}} \mathrm{A}_{\mathrm{k}}\right]}{\mathrm{L}_{\mathrm{j}}}$

Where for a trip $j$ undertaken by driver $m, A_{k}$ is the area delineated by the vehicle speed and

3 the speed threshold when the vehicle speed is greater than the specific threshold, $n$ is the number

4 of cases during the trip $j$ when the vehicle speed is greater than the speed threshold, and $L_{j}$ is the

5 length of trip $j$. Note that for the calculation of the overall speed metric, the posted speed limit

6 was specified as the speed threshold (Pantangi et al., 2019).

7

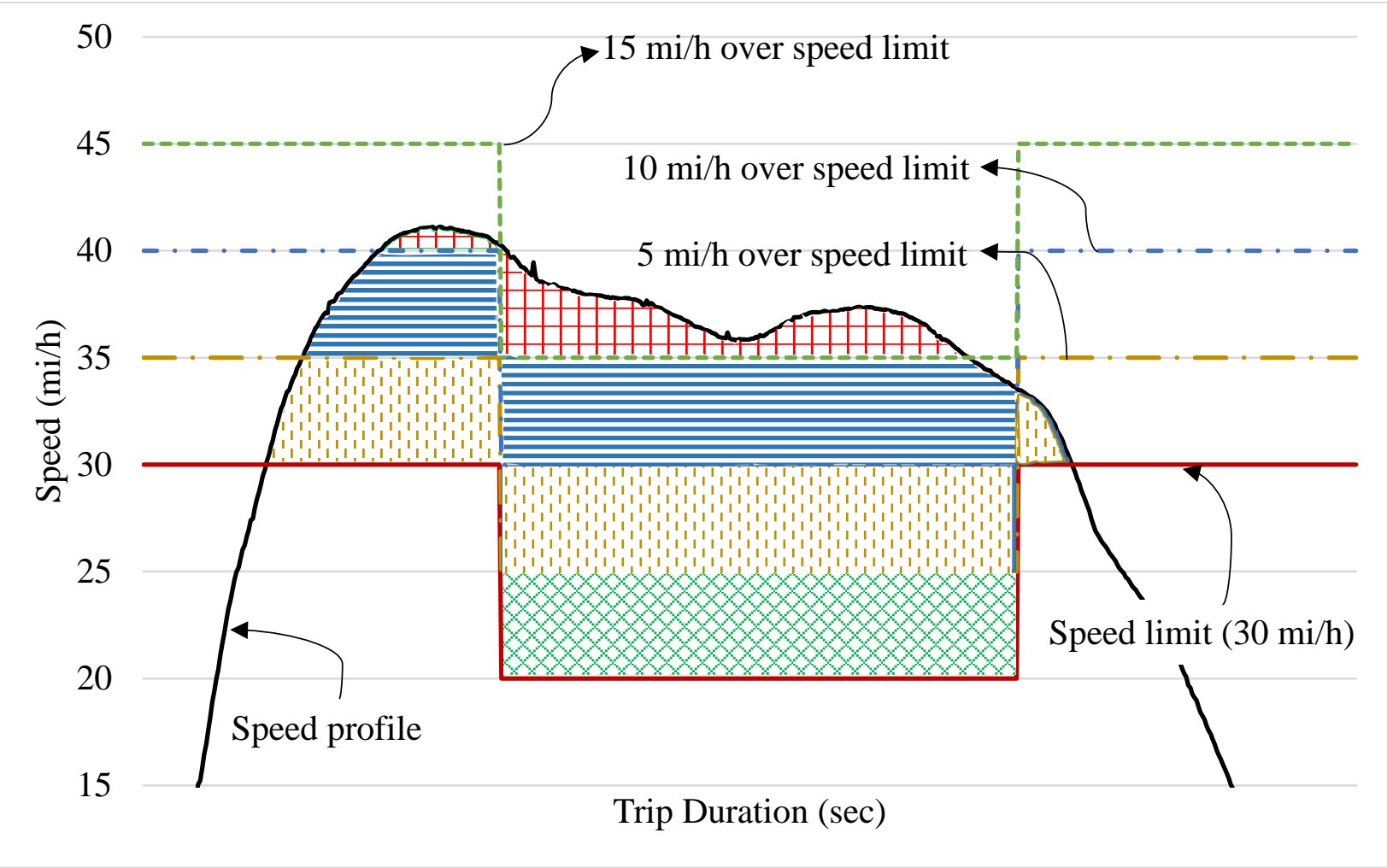

Figure 2. Graphical Illustration of the Scaled Speed Metrics using Four Speed Thresholds.

Tailgating (following too closely) is defined to occur when the following headway with the

12 lead vehicle is less than 2 seconds (Song and Wang, 2010). Scaled tailgating metrics are also

13 calculated in similar fashion to the scaled speeding metrics. Specifically, the presence of a lead 
1 vehicle was confirmed from the time series data and the forward-facing videos and then the metrics

2 were calculated only if the speed of the vehicle was at-least 90 percent of the speed limit. This

3 condition allows for the identification of free-flow conditions through the elimination of cases

4 when driving behavior was influenced by traffic control devices or by queueing incidents being

5 present in the traffic stream. To account for differences in the degree of tailgating as well as to

6 provide a clear distinction between trips with significant but short tailgating and trips with limited

7 tailgating of long duration, scaled metrics are developed. Specifically, three tailgating thresholds

8 are considered: 2, 1.5, 1 and 0.5 seconds of headway with the lead vehicle. The scaled metrics are

9 calculated as the area between each specific tailgating threshold and the actual headway with the

10 lead vehicle. Figure 3 provides a graphical illustration of the headway thresholds and the

11 corresponding scaled tailgating metrics.

12

13

14

15

16

17

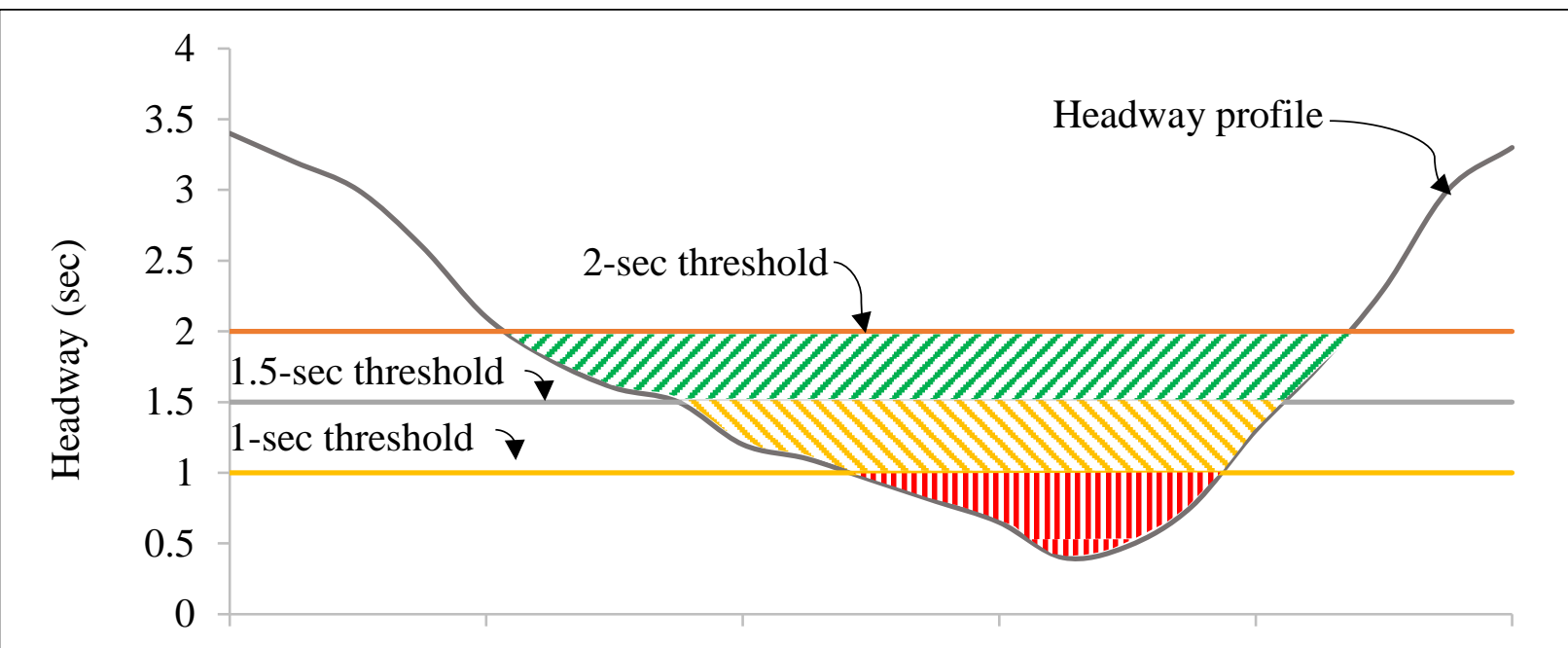

Trip duration

Figure 3. Graphical Illustration of the Scaled Tailgating Metrics using Three Headway Thresholds. 
Speeding and tailgating behavioral patterns at different thresholds may share some is presented below:

$$
\begin{aligned}
& Y_{1}=\boldsymbol{\beta}_{1} \mathbf{X}+\varepsilon_{1} \\
& Y_{2}=\boldsymbol{\beta}_{2} \mathbf{X}+\varepsilon_{1} \\
& Y_{3}=\boldsymbol{\beta}_{3} \mathbf{X}+\varepsilon_{2}
\end{aligned}
$$

9

.

$$
Y_{k}=\boldsymbol{\beta}_{k} \mathbf{X}+\varepsilon_{i}
$$

common unobserved characteristics, which can lead to cross-equation error term correlation among the scaled metrics. Since the traditional univariate regression approaches cannot address this type of correlation, the Seemingly Unrelated Regression Equation (SURE) modeling approach is employed. The latter has the potential to account for unobserved factors that may be common among the scaled speeding and tailgating metrics through their simultaneous modeling. The model formulation of the SURE model (Washington et al., 2011; Anastasopoulos and Mannering, 2016;)

where, $Y$ is the speeding or tailgating area for trip $i, 1$ through $\mathrm{k}$ represent the speeding or tailgating categories as described previously, $\mathbf{X}_{i}$ is a vector of trip i's characteristics (e.g., HVE implementation, roadway or roadside conditions, weather characteristics, and driver/vehicle/trip attributes), $\boldsymbol{\beta}$ represent vectors of estimable parameters; and $\varepsilon$ denote disturbance terms. Since multiple trips are undertaken by each participant, the observed speeding and tailgating patterns may be subject to unobserved variations that are commonly shared within each group of participant-specific trips. These unobserved variations may take the form of panel effects, which,

7 if not taken into account in statistical modeling, could lead to biased predictors and erroneous statistical inference (Washington et al., 2011; Eker et al., 2019). To that end, for the estimation of 
1 the SURE models, the Generalized Least Square (GLS) estimation technique is employed

2 (Washington et al., 2011; Anastasopoulos and Mannering, 2016).

Unsafe lane changes were identified when at least one of the following traffic incidents was observed: (i) non-use of turn signals to indicate lane changes; (ii) changing lanes abruptly; (iii) performing lane changes too close to lead vehicle or without regard to vehicles in adjacent lanes. It should be noted that any lane change incident was primarily identified through the video processing of traversals. The information from the video processing was coupled with the time series data in order to determine whether the NDS driver performed a lane change with or without with their zero-inflated counterparts) and ordered probability approaches were both investigated.

11 Due to the limited range of unsafe lane changes per trip, a grouped random parameters ordered probit model with heterogeneity in means was employed, with the ordered outcomes ranging from 0 to 3 or more unsafe lane changes. Such a modeling approach addresses unobserved heterogeneity and panel effects simultaneously (Washington et al., 2011; Behnood and Mannering, 2017a; 2017b; Fountas and Anastasopoulos, 2017; Seraneeprakarn et al., 2017; Fountas and Anastasopoulos, 2018; Fountas et al., 2018b; 2018c). The ordered probit model is defined as (Chen et al., 2016; Fountas and Anastasopoulos, 2018; Lee et al., 2018; Fountas and Rye, 2019): where, $y$ is the number of unsafe lane changes $(0,1,2$, and 3 or more) occurring in each trip $i, \boldsymbol{\beta}$ denotes a vector of estimable parameters, $\mathbf{X}$ is a vector of explanatory variables, $\mu$ are threshold limits that determine y, which are estimated along with $\boldsymbol{\beta}$ and $\varepsilon$ are random disturbance terms following a normal distribution with mean 0 and variance equal to 1 . To account for unobserved heterogeneity and panel effects, $\boldsymbol{\beta}$ s are allowed to vary across the observations and are 
1 estimated as (Anastasopoulos and Mannering, 2009; Anastasopoulos et al., 2012; 2016; Russo et

2 al., 2014; Sarwar et al., 2017b; Cai et al., 2018):

$3 \quad \boldsymbol{\beta}_{\text {in }}=\boldsymbol{\beta}+\varphi_{n}$

4 where, $\boldsymbol{\beta}$ is the vector with the mean values of the random parameters for each driver $n$, and $\phi$ is a

5 randomly distributed disturbance term that captures unobserved characteristics and varies across

6 the participants.

'Other’ aggressive driving behavior types include incidents of not-yielding right-of-way as

8 well as red light or stop sign violations, which were identified through the analysis of forward-

9 facing videos of traversals. To investigate the likelihood of occurrence of 'other' aggressive

10 driving events, a correlated grouped random parameters binary logit model is estimated (Yu et al.,

11 2015; Fountas et al., 2018a; Fountas et al., 2019; Jordan et al., 2019; Eker et al., 2019). This

12 modeling approach can account for the independent and interactive effect of unobserved factors

13 that may affect participants' driving patterns as well as for panel effects emerging due to multiple

14 trips conducted by the same participant. The occurrence of 'other' aggressive driving behavior 15 types can be defined using the function $\mathrm{A}_{\text {in }}$ for each trip $i$, as (Anastasopoulos and Mannering, 16 2011):

$$
A_{\text {in }}=\boldsymbol{\beta}_{\text {in }} \mathbf{X}_{\text {in }}+\varepsilon_{\text {in }}
$$

18 To account for panel effects, unobserved heterogeneity and correlation among pairs of random 19 parameters, individual $\boldsymbol{\beta}$ s are estimated for each driver, as (Greene, 2012):

$$
\boldsymbol{\beta}_{i}=\beta+\Gamma \delta_{i}
$$


1 where, $\beta$ is the mean of random parameter, $\Gamma$ is a Cholesky matrix that includes the elements used

2 for computation of standard deviations of random parameters, and $\delta$ is randomly distributed term

3 with mean 0 and variance equal to 1 .

$4 \quad$ The random parameter models are estimated using a simulated maximum likelihood

5 estimation technique. For the numerical integrations that are conducted throughout the simulated

6 procedure, we employed Halton sequence draws (Halton, 1960; Train, 2003; Bhat, 2003). The

7 models were estimated using 1,200 Halton draws, which were identified to be the minimum

8 number of draws that resulted in the estimation of models with stable parameters.

\section{MODEL ESTIMATION AND RESULTS}

10 Table 2 shows the estimation results of the SURE model for the scaled speeding metrics. Focusing

11 on the effect of HVE programs, the variable reflecting trips conducted during May (i.e., the month

12 when the HVE program was implemented) in control areas results in reduction in the extent and

13 duration of speeding up to $5 \mathrm{mi} / \mathrm{h}$ over the speed limit, up to $10 \mathrm{mi} / \mathrm{h}$ over the speed limit and up

14 to $15 \mathrm{mi} / \mathrm{h}$ over the speed limit. Given that the majority of control areas are closely located to the

15 enforcement areas, this finding may constitute an indication that drivers' awareness about the HVE implementation is likely to reduce speeding.

Various driver characteristics are also found to affect the scaled speeding metrics. White participants driving in areas of HVE program implementation are associated with speeding greater than $15 \mathrm{mi} / \mathrm{h}$ over speed limit. Younger participants (younger than 35 years old) are associated

20 with greater extent and duration of speeding, as the relevant variable results in an increase of

21 speeding, for the majority of the scaled speed metrics. Furthermore, participants between 35 and

2249 years old are also associated with speeding behavior, primarily exhibiting speeding up to 10

$23 \mathrm{mi} / \mathrm{h}$ over the speed limit. Such an increase in the lowest speed metrics may be capturing the 
1 behavioral propensity of these drivers to exceed the speed limit to the extent they do not expect

2 undesirable or uncomfortable driving circumstances. Drivers of African American, Asian,

3 Alaskan Indian or American Indian origin are associated with speeding behavior, only for the

4 lowest speeding interval (up to $5 \mathrm{mi} / \mathrm{h}$ over the speed limit). For the same drivers, the scaled metric

5 reflecting speeding between $10 \mathrm{mi} / \mathrm{h}$ and $15 \mathrm{mi} / \mathrm{h}$ over the speed limit is found to decrease. This

6 finding may be capturing variations associated with the habitual driving patterns of these drivers.

7 The drivers may possibly anticipate that the enforcement program targets on higher degrees of

8 speeding (e.g., more than $10 \mathrm{mi} / \mathrm{h}$ over the speed limit), therefore they adjust their driving behavior

9 accordingly.

With regards to the trip characteristics, the trip duration and average trip speed are also

11 found to be statistically significant determinants of the metrics reflecting speeding up to $5 \mathrm{mi} / \mathrm{h}$

12 and up to $10 \mathrm{mi} / \mathrm{h}$ over the speed limit. As far as the socio-demographic characteristics are

13 concerned, participants who do not work full time and participants with some level of high school

14 education who live in a single-parent household are more likely to exhibit speeding behavior.

15 Household income has a mixed effect on speeding behavior. Participants from households with

16 annual income between $\$ 40,000$ and $\$ 99,999$ are associated with speeding behavior (speeding up

17 to $10 \mathrm{mi} / \mathrm{h}$ over the speed limit). In contrast, the variable reflecting households with annual income

18 greater than $\$ 100,000$ is found to decrease speeding in the range between $10 \mathrm{mi} / \mathrm{h}$ and $15 \mathrm{mi} / \mathrm{h}$

19 over the speed limit. Participants who drive SUVs or passenger cars are associated with speeding

20 up to $5 \mathrm{mi} / \mathrm{h}$ over the speed limit. This finding could be reflecting a common tendency of most

21 road users to employ speeds greater but close to the speed limit; at such speeds, drivers may feel

22 more comfortable and may not expect to be cited for speeding violations. 
Participants who were involved in at-least one accident or violation in their lifetime and drove over 15,000 miles in the previous year are found to exhibit speeding behavior, especially in the range between $5 \mathrm{mi} / \mathrm{h}$ and $10 \mathrm{mi} / \mathrm{h}$ over the speed limit. This result may be possibly capturing an overall risk-taking behavior of these participants, which may be enhanced by their considerable driving experience. In addition, the metric reflecting speeding between $10 \mathrm{mi} / \mathrm{h}$ and $15 \mathrm{mi} / \mathrm{h}$ over the speed limit is found to increase amongst drivers who drove less than 25,000 miles in the previous year. In contrast, the speed metric reflecting speeding up to $5 \mathrm{mi} / \mathrm{h}$ over the speed limit is found to decrease for drivers whose driving training was informally provided by parents or friends as well as for drivers who had post-licensure driving skills training.

Focusing on the impact of vehicle characteristics, vehicle age is a statistically significant determinant of the metric reflecting speeding between $5 \mathrm{mi} / \mathrm{h}$ and $10 \mathrm{mi} / \mathrm{h}$ over the speed limit. Interestingly, driving older cars (over 5 years old) is found to reduce the metric indicating speeding greater than $15 \mathrm{mi} / \mathrm{h}$ over speed limit. This finding possibly captures the risk-compensating behavior of drivers when they drive older cars, because they may expect lower vehicle performance or safety level, especially in high-speed driving maneuvers. Vehicles used for business purposes are also found to decrease metrics reflecting speeding between $5 \mathrm{mi} / \mathrm{h}$ and 15 $\mathrm{mi} / \mathrm{h}$ over the speed limit. The use of such vehicles likely reflects business-related trips, for which drivers may exhibit greater driving caution.

With regard to the effect of trip frequency, participants who made less than 10 trips in the study period are associated with speeding lower than $5 \mathrm{mi} / \mathrm{h}$ over the speed limit. This finding may capture either the limited awareness of these drivers about the enforcement program, or their habitual driving patterns, which are not affected by the enforcement program even in the shortterm. 
Drivers whose Barkley questionnaire score was less than 7 are less likely to exhibit

2 speeding behavior; note that, according to the SHRP2 NDS Insight Website, score greater than or

3 equal to 7 is indicative of Attention Deficit Hyperactivity Disorder. This finding is intuitive as

4 these respondents are less likely to suffer from Attention Deficit Hyperactivity Disorder. In

5 addition, drivers who do not perceive various aggressive driving patterns (e.g., speeding at greater

6 speeds, not waiting before starting as soon as the traffic light turns green, driving to reduce tension,

7 and performing secondary tasks while driving) as risk-taking behavioral elements are associated

8 with reduction in speed metric reflecting speeding up to $5 \mathrm{mi} / \mathrm{h}$ over speed limit. In contrast,

9 drivers who do not perceive high risk in making illegal turns, indulging in road-rage (e.g., cutting

10 off other road users, honking, or yelling) or using drug or alcohol during the driving task are found

11 to exhibit speeding behavior, especially for the range between the speed limit and $5 \mathrm{mi} / \mathrm{h}$ over the

12 speed limit. 
Table 2. Estimation Results of the SURE Model for Scaled Speed Metrics

\begin{tabular}{|c|c|c|c|c|c|c|c|c|}
\hline Variable & $\begin{array}{l}\text { Speed } \\
\text { (between } \\
\text { limit and } \\
\text { above spee }\end{array}$ & $\begin{array}{r}\text { metric } \\
\text { speed } \\
5 \text { mph } \\
\text { d limit) }\end{array}$ & $\begin{array}{l}\text { Speed } \\
\text { (between } \\
\text { mph abov } \\
\text { limit) }\end{array}$ & $\begin{array}{r}\text { metric } \\
5 \text { and } 10 \\
\text { e speed }\end{array}$ & $\begin{array}{l}\text { Speed } \\
\text { (betwee } \\
15 \mathrm{mp} \\
\text { speed li }\end{array}$ & $\begin{array}{l}\text { metric } \\
10 \text { and } \\
\text { above } \\
\text { t) }\end{array}$ & $\begin{array}{l}\text { Speed } \\
\text { (greater } \\
\text { mph } \\
\text { speed li }\end{array}$ & $\begin{array}{l}\text { metric } \\
\text { than } 15 \\
\text { above } \\
\text { nit) }\end{array}$ \\
\hline & Coeff. & $t$-stat & Coeff. & $t$-stat & Coeff. & $t$-stat & Coeff. & $t$-stat \\
\hline Constant & 20.816 & 3.060 & - & - & - & - & - & - \\
\hline $\begin{array}{l}\text { Age indicator ( } 1 \text { if participant's age is less than } 35 \text { years, } 0 \\
\text { otherwise) }\end{array}$ & 18.482 & 7.710 & 8.742 & 6.520 & 1.761 & 4.270 & - & - \\
\hline $\begin{array}{l}\text { Work status indicator ( } 1 \text { if participant does not work full time, } \\
0 \text { otherwise) }\end{array}$ & 11.859 & 5.150 & 3.178 & 2.690 & - & - & - & - \\
\hline $\begin{array}{l}\text { Household/Education indicator ( } 1 \text { if participant lives in one- } \\
\text { parent household or alone and has some high school } \\
\text { education, } 0 \text { otherwise) }\end{array}$ & 7.877 & 3.460 & 3.402 & 3.070 & - & - & - & - \\
\hline Number of vehicles in household & 4.518 & 5.910 & - & - & - & - & - & - \\
\hline $\begin{array}{l}\text { Trip area/Month indicator ( } 1 \text { if trip made in control area in the } \\
\text { month of May, } 0 \text { otherwise) }\end{array}$ & -7.979 & -3.860 & -4.659 & -3.750 & -0.851 & -1.980 & - & - \\
\hline $\begin{array}{l}\text { Income indicator( } 1 \text { if household income is between } \$ 40,000 \\
\text { and } \$ 99,999,0 \text { otherwise) }\end{array}$ & 13.911 & 7.320 & 6.837 & 6.620 & - & - & - & - \\
\hline $\begin{array}{l}\text { Age indicator ( } 1 \text { if participant's age is between } 35 \text { and } 49 \text { years, } \\
0 \text { otherwise) }\end{array}$ & 18.364 & 6.350 & 5.239 & 3.520 & - & - & - & - \\
\hline $\begin{array}{l}\text { ADHD indicator ( } 1 \text { if Barkley's score is less than } 7,0 \\
\text { otherwise) }\end{array}$ & -9.833 & -2.430 & - & - & - & - & - & - \\
\hline $\begin{array}{l}\text { Vehicle type indicator ( } 1 \text { if participant drove Car or SUV } \\
\text { crossover, } 0 \text { otherwise) }\end{array}$ & 7.575 & 3.150 & - & - & - & - & - & - \\
\hline $\begin{array}{l}\text { Risk perception indicator ( } 1 \text { if participant doesn't perceive } \\
\text { great risk in trying to be first off the line when light turns } \\
\text { green, driving } 10-20 \mathrm{mph} \text { above speed limit or driving more } \\
\text { than } 20 \mathrm{mph} \text { over speed limit, } 0 \text { otherwise) }\end{array}$ & -7.554 & -2.580 & - & - & - & - & - & - \\
\hline $\begin{array}{l}\text { Trip frequency indicator ( } 1 \text { if the participant undertook less } \\
\text { than } 10 \text { trips, } 0 \text { otherwise) }\end{array}$ & 4.906 & 2.830 & - & - & - & - & - & - \\
\hline $\begin{array}{l}\text { Risk perception indicator ( } 1 \text { if participant doesn't perceive } \\
\text { great risk in making illegal turns, } 0 \text { otherwise) }\end{array}$ & 7.178 & 3.780 & - & - & - & - & - & - \\
\hline Square of average trip speed $\left(\mathrm{mph}^{2}\right)$ & 0.039 & 9.250 & 0.008 & 5.360 & - & - & 0.002 & 3.060 \\
\hline Average trip speed (mph) & -2.227 & -7.110 & -0.472 & -4.780 & - & - & - & - \\
\hline
\end{tabular}




\begin{tabular}{|c|c|c|c|c|c|c|c|c|}
\hline Variable & \multicolumn{2}{|c|}{$\begin{array}{l}\text { Speed } r \text { metric } \\
\text { (between } \text { speed } \\
\text { limit and } 5 \text { mph } \\
\text { above speed limit) }\end{array}$} & \multicolumn{2}{|c|}{$\begin{array}{l}\text { Speed metric } \\
\text { (between } 5 \text { and } 10 \\
\text { mph above speed } \\
\text { limit) }\end{array}$} & \multicolumn{2}{|c|}{$\begin{array}{l}\text { Speed metric } \\
\text { (between } 10 \text { and } \\
15 \text { mph above } \\
\text { speed limit) }\end{array}$} & \multicolumn{2}{|c|}{$\begin{array}{l}\text { Speed metric } \\
\text { (greater than } 15 \\
\text { mph above } \\
\text { speed limit) }\end{array}$} \\
\hline Trip Duration (secs) & 0.083 & 5.360 & 0.025 & 3.310 & - & - & - & - \\
\hline $\begin{array}{l}\text { Race indicator ( } 1 \text { if participant is American Indian, Alaskan } \\
\text { Indian, Asian or African American, } 0 \text { otherwise) }\end{array}$ & 7.049 & 2.480 & - & - & -1.474 & -2.320 & - & - \\
\hline $\begin{array}{l}\text { Risk perception indicator ( } 1 \text { if participant doesn't perceive } \\
\text { great risk in drinking alcohol or using recreational drugs } \\
\text { while driving, } 0 \text { otherwise) }\end{array}$ & 14.189 & 3.780 & - & - & - & - & - & - \\
\hline $\begin{array}{l}\text { Driver training indicator ( } 1 \text { if participant was trained } \\
\text { informally by parent, family friend or friend, } 0 \text { otherwise })\end{array}$ & -3.227 & -1.820 & - & - & - & - & - & - \\
\hline $\begin{array}{l}\text { Risk perception indicator ( } 1 \text { if participant doesn't perceive } \\
\text { great risk in driving to reduce tension, } 0 \text { otherwise) }\end{array}$ & -3.480 & -1.740 & - & - & - & - & - & - \\
\hline $\begin{array}{l}\text { Risk perception indicator ( } 1 \text { if participant doesn't perceive } \\
\text { immense risk in performing other things while driving, like } \\
\text { cell-phone usage, eating or drinking etc., } 0 \text { otherwise) }\end{array}$ & -6.920 & -3.300 & -4.333 & -4.290 & - & - & - & - \\
\hline $\begin{array}{l}\text { Driver Miles/Accidents/Violations indicator ( } 1 \text { if the } \\
\text { participant drove greater than } 15,000 \text { miles in the previous } \\
\text { year and has had at-least one accident or violation in their } \\
\text { lifetime, } 0 \text { otherwise) }\end{array}$ & - & - & 2.468 & 3.180 & - & - & - & - \\
\hline $\begin{array}{l}\text { Risk perception indicator ( } 1 \text { if participant doesn't perceive } \\
\text { immense risk in driving while sleepy and when hard to keep } \\
\text { eyes open, } 0 \text { otherwise) }\end{array}$ & - & - & -3.526 & -3.550 & -2.164 & -5.140 & - & - \\
\hline $\begin{array}{l}\text { Use of study vehicle indicator ( } 1 \text { if vehicle used for business } \\
\text { purpose, } 0 \text { otherwise) }\end{array}$ & - & - & -6.587 & -3.910 & -2.641 & -3.820 & - & - \\
\hline $\begin{array}{l}\text { Risk perception indicator ( } 1 \text { if participant doesn't perceive any } \\
\text { great risk in cutting off, honking or yelling at other drivers } \\
\text { who drive slowly or cut the participant off, } 0 \text { otherwise) }\end{array}$ & - & - & 4.248 & 4.120 & 1.693 & 3.650 & - & - \\
\hline $\begin{array}{l}\text { Risk perception indicator ( } 1 \text { if participant doesn't perceive } \\
\text { great risk in drinking alcohol or using recreational drugs } \\
\text { while or before driving, } 0 \text { otherwise) }\end{array}$ & - & - & 5.337 & 3.900 & 1.764 & 2.990 & - & - \\
\hline
\end{tabular}




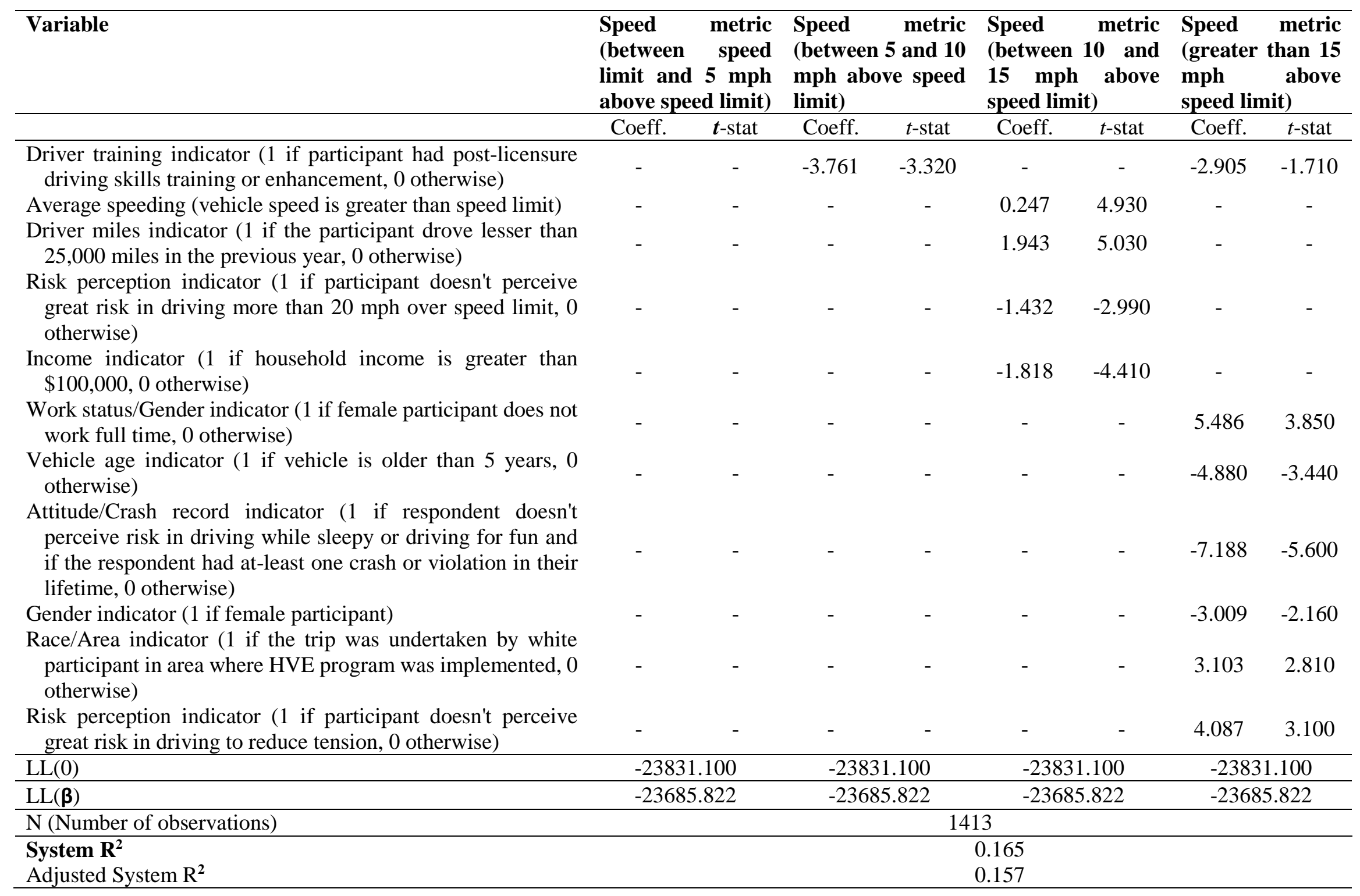


Table 3 provides the estimation results of the SURE model for the scaled tailgating metrics.

2 Similar to the speeding model, the variable representing trips conducted during May (month of

3 HVE implementation) in control areas is found to decrease the scaled tailgating metrics reflecting

4 headways between 2 seconds and 1 second. This finding constitutes another indication that the

5 awareness of drivers about the HVE implementation in adjacent areas (note that the majority of

6 control areas are located in the proximity of HVE implementation areas) may result in adjustment

7 of their driving behavior. In conjunction with the similar finding drawn from the speeding model,

8 there seems to exist a residual spatial spillover effect of the HVE implementation that positively

9 (by reducing tailgating) affects driving behavior.

Drivers younger than 49 years old are associated with increase in tailgating metrics

11 reflecting headway between 2 seconds and 1 second. This is consistent with the findings from the

12 speeding model and may capture unobserved effects relating to the risk-taking behaviors of

13 drivers. In contrast, trips made by older drivers (older than 65 years old) are associated with a

14 reduction in the tailgating metric reflecting a headway less than 1 second. This finding is intuitive

15 since older drivers are more likely to show risk-averse driving behavior. Drivers of American

16 Indian, Alaskan Indian, Asian or African American origin are associated with tailgating behavior,

17 when consideration is given to headway between 2 seconds and 1.5 seconds. In consistency with

18 similar findings from the speeding model, this group of drivers is more likely to exhibit tailgating

19 behavior, but to the lowest degree.

With regard to the effect of education level, drivers with post-college or higher level of

21 education are associated with tailgating behavior, especially when the headway with the lead

22 vehicle is between 1.5 seconds and 1 second. Similarly, the tailgating metric reflecting headway

23 less than 2 seconds but greater than 1 second is found to increase for participants from single- 
1 parent households with some high-school education. In contrast, the tailgating metric reflecting

2 headway between 2 seconds and 1 second is found to decrease among drivers who were trained by

3 parents or friends. Participants who drive more than 15,000 miles on an annual basis are associated

4 with an increase in tailgating metrics, for all the headway intervals; in line with similar results

5 from the speeding model, this finding may be picking up the effect of drivers' self-efficacy on

6 their driving patterns, even when traveling across enforcement areas.

$7 \quad$ Focusing on the trip characteristics, the number of traffic signals encountered throughout

8 a trip is found to decrease all tailgating metrics. The expectations of drivers for frequent and

9 possibly abrupt slowdowns, due to the presence of traffic signals, may discourage them from

10 following the lead vehicle too closely. Morning trips (conducted between 6 am and noon) as well

11 as evening trips (conducted between $6 \mathrm{pm}$ and $9 \mathrm{pm}$ ) are also associated with a decrease in the

12 tailgating metrics. Such time-slots include morning and evening peak hours, during which the

13 likelihood of traffic congestion is significant. The latter may prevent drivers from exhibiting

14 tailgating behavior. The average trip speed is found to increase tailgating metrics reflecting

15 headways between 2 seconds and 1.5 seconds and less than 1 second. Higher average speeding

16 during a trip is found to increase tailgating with a headway less than 1 second. This may capture

17 an overall risk-taking behavior of drivers resulting in both speeding and tailgating. Greater trip

18 duration is found to increase the tailgating metric for a headway between 2 seconds and 1.5

19 seconds. Frequent travelers (i.e., drivers who conducted more than 5 trips throughout the same

20 location during the study period) are associated with a reduction in the tailgating metric reflecting

21 headway less than 1 second. This effect is intuitive, as high trip frequency may indicate drivers’

22 awareness about the implementation of the enforcement program. 
With respect to risk perception characteristics of participants, drivers who do not perceive

2 significant risk in undertaking illegal turns or driving to reduce tension, are overall associated with

3 tailgating behavior. In contrast, drivers who do not perceive great risk in speeding more than 20

4 mph over the speed limit are associated with reductions in the tailgating metrics reflecting

5 headways less than 1.5 seconds. This finding may capture the behavioral patterns of drivers who

6 possibly consider tailgating as a more risk-taking endeavor than speeding. 
Table 3. Estimation Results of the SURE Model for Tailgating Metrics

\begin{tabular}{|c|c|c|c|c|c|c|}
\hline \multirow[t]{2}{*}{ Variable } & \multicolumn{2}{|c|}{$\begin{array}{l}\text { Tailgating retric } \\
\text { (Following headway } \\
\text { between } 2 \mathrm{~s} \text { and } 1.5 \mathrm{~s} \text { ) }\end{array}$} & \multicolumn{2}{|c|}{$\begin{array}{l}\text { Tailgating metric } \\
\text { (Following headway } \\
\text { between } 1.5 \mathrm{~s} \text { and } 1 \mathrm{~s} \text { ) }\end{array}$} & \multicolumn{2}{|c|}{$\begin{array}{l}\text { Tailgating metric } \\
\text { (Following headway } \\
\text { less than } 1 \text { s) }\end{array}$} \\
\hline & Coeff. & t-stat & Coeff. & t-stat & Coeff. & t-stat \\
\hline Constant & -2.103 & -2.240 & -1.389 & -3.210 & - & - \\
\hline $\begin{array}{l}\text { Age indicator ( } 1 \text { if participant's age is less than } 35 \text { years, } 0 \\
\text { otherwise) }\end{array}$ & 2.264 & 4.420 & 1.403 & 4.600 & - & - \\
\hline $\begin{array}{l}\text { Trip area/Month indicator ( } 1 \text { if trip made in control area in } \\
\text { the month of May, } 0 \text { otherwise) }\end{array}$ & -1.706 & -3.900 & -0.690 & -3.010 & - & - \\
\hline $\begin{array}{l}\text { Age indicator ( } 1 \text { if participant's age between } 35 \text { and } 49 \\
\text { years, } 0 \text { otherwise) }\end{array}$ & 2.313 & 3.600 & 1.248 & 3.480 & - & - \\
\hline Trip Duration (secs) & 0.005 & 2.680 & - & - & - & - \\
\hline $\begin{array}{l}\text { Race indicator ( } 1 \text { if participant is American Indian, Alaskan } \\
\text { Indian, Asian or African American, } 0 \text { otherwise) }\end{array}$ & 0.893 & 2.220 & - & - & - & - \\
\hline $\begin{array}{l}\text { Driver training indicator ( } 1 \text { if participant was trained } \\
\text { informally by parent, family friend or friend, } 0 \text { otherwise) }\end{array}$ & -1.074 & -2.090 & -0.731 & -2.680 & - & - \\
\hline $\begin{array}{l}\text { Risk perception indicator ( } 1 \text { if participant doesn't perceive } \\
\text { great risk in making illegal turns, } 0 \text { otherwise) }\end{array}$ & 1.304 & 2.490 & 0.805 & 2.300 & 0.366 & 2.250 \\
\hline $\begin{array}{l}\text { Household/Education indicator ( } 1 \text { if participant lives in } \\
\text { one-parent household or alone and has some high school } \\
\text { education, } 0 \text { otherwise) }\end{array}$ & 1.590 & 3.440 & 1.138 & 4.360 & - & - \\
\hline Average trip speed (mph) & 0.106 & 5.820 & - & - & 0.015 & 2.750 \\
\hline $\begin{array}{l}\text { Driver Miles indicator ( } 1 \text { if the participant drove more than } \\
15,000 \text { miles in the previous year, } 0 \text { otherwise) }\end{array}$ & 2.246 & 4.010 & 1.541 & 4.100 & 0.618 & 3.520 \\
\hline $\begin{array}{l}\text { Time of trip indicator ( } 1 \text { if trip was made between } 6 \text { am and } \\
12 \text { or between } 3 \text { pm and } 9 \text { pm, } 0 \text { otherwise) }\end{array}$ & -0.729 & -2.510 & - & - & - & - \\
\hline Number of traffic signals in a trip & -1.377 & -3.560 & -0.624 & -2.500 & -0.190 & -1.650 \\
\hline Square of average trip speed $\left(\mathrm{mph}^{2}\right)$ & - & - & 0.001 & 4.540 & - & - \\
\hline Vehicle age (years) & - & - & 0.146 & 4.020 & 0.148 & 5.640 \\
\hline $\begin{array}{l}\text { Risk perception indicator ( } 1 \text { if participant doesn't perceive } \\
\text { great risk in driving to reduce tension, } 0 \text { otherwise) }\end{array}$ & - & - & 0.332 & 2.180 & - & - \\
\hline $\begin{array}{l}\text { Risk perception indicator ( } 1 \text { if participant doesn't perceive } \\
\text { great risk in driving more than } 20 \text { mph over speed limit, } \\
0 \text { otherwise) }\end{array}$ & - & - & -0.394 & -1.850 & -0.275 & -1.730 \\
\hline
\end{tabular}




\begin{tabular}{|c|c|c|c|c|c|c|}
\hline \multirow[t]{2}{*}{ Variable } & \multirow{2}{*}{ 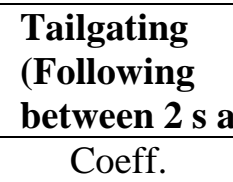 } & $\begin{array}{l}\text { metric } \\
\text { headway } \\
\text { ind } 1.5 \mathrm{~s} \text { ) }\end{array}$ & \multirow{2}{*}{$\begin{array}{c}\begin{array}{c}\text { Tailgating } \\
\text { (Following } \\
\text { between 1.5 }\end{array} \\
\text { Coeff. } \\
\end{array}$} & $\begin{array}{r}\text { metric } \\
\text { headway } \\
\text { s and } 1 \mathrm{~s})\end{array}$ & \multicolumn{2}{|c|}{$\begin{array}{l}\text { Tailgating metric } \\
\text { (Following headway } \\
\text { less than } 1 \mathrm{~s} \text { ) }\end{array}$} \\
\hline & & $t$-stat & & $t$-stat & Coeff. & t-stat \\
\hline $\begin{array}{l}\text { Education level indicator ( } 1 \text { if participant had some post- } \\
\text { graduate education or has an advanced degree ,0 } \\
\text { otherwise) }\end{array}$ & - & - & 0.510 & 3.200 & - & - \\
\hline $\begin{array}{l}\text { Participant age indicator ( } 1 \text { if the participant is older than } \\
65 \text { years, } 0 \text { otherwise) }\end{array}$ & - & - & - & - & -0.282 & -2.070 \\
\hline $\begin{array}{l}\text { Average speeding (average vehicle speed greater than } \\
\text { speed limit) }\end{array}$ & - & - & - & - & 0.073 & 3.440 \\
\hline $\begin{array}{l}\text { Trip frequency indicator ( } 1 \text { if the participant undertook } \\
\text { more than } 5 \text { trips, } 0 \text { otherwise) }\end{array}$ & - & - & - & - & -0.934 & -4.340 \\
\hline $\mathrm{LL}(0)$ & \multicolumn{2}{|c|}{-7780.461} & \multicolumn{2}{|c|}{$\begin{array}{l}-7780.461 \\
\end{array}$} & \multicolumn{2}{|c|}{-7780.461} \\
\hline $\operatorname{LL}(\boldsymbol{\beta})$ & \multicolumn{2}{|c|}{-7758.894} & \multicolumn{2}{|c|}{-7758.894} & \multicolumn{2}{|c|}{-7758.894} \\
\hline $\mathrm{N}$ (Number of observations) & \multicolumn{6}{|c|}{1037} \\
\hline $\begin{array}{l}\text { System } \mathrm{R}^{2} \\
\text { Adjusted System } \mathrm{R}^{2}\end{array}$ & \multicolumn{6}{|c|}{0.136} \\
\hline
\end{tabular}


Table 4 presents the estimation results of the grouped random parameters ordered probit model with heterogeneity in means for unsafe lane changes. Specifically, trips conducted during the months of May, June or July in areas of HVE implementation are associated with a reduction (by -0.003) in the likelihood of occurrence of 3 or more unsafe lane changes. This possibly reflects temporal spillover effects of the implementation of HVE in terms of improving driving behavior by reducing the occurrence of unsafe lane changes.

Focusing on the driver-specific characteristics, the majority of trips $(70.20 \%)$ made by drivers with at least one crash or traffic violation during their lifetime are more likely to result in 3 or more unsafe lane changes. In contrast, $76.80 \%$ of trips made by drivers with high trip frequency (i.e., drivers who conducted more than 5 trips throughout the same location during the study period) are associated with higher probability of zero unsafe lane changes. This finding is consistent with the relevant results of speeding and tailgating models, and possibly reflects the awareness of frequent travelers about the implementation of HVE program.

The use of older cars (older than 5 years) is found to decrease (by 0.001) the probability of unsafe lane change occurrence throughout the trip possibly reflecting risk-compensating behavior of old vehicles' users. In contrast, the probability of unsafe lane changes occurrence increases in trips made by drivers involved in multi-member households with more than 2 vehicles. This finding may be capturing unobserved effects arising from the driving experience or driving confidence of these individuals. Similarly, drivers who live in their own house for more than 5 years are more likely to perform 3 or more unsafe lane changes throughout the trip. Such a propensity could be attributed to the familiarity of this group of drivers with the roadway- or traffic-specific characteristics of the trip area. In addition, almost half of the trips made with passenger cars or pickup trucks are found to be associated with 3 or more unsafe lane changes. 
To account for heterogeneity patterns arising from unobserved driver-, roadway- or

2 vehicle-specific characteristics, heterogeneity in the means of random parameters has been

3 introduced (Mannering et al., 2016; Behnood and Mannering, 2017a; Behnood and Mannering,

4 2017b). Specifically, greater number of vehicles in the household is found to decrease the means

5 of the random parameters representing drivers having at least 1 crash or violation in their driving

6 past and drivers using cars or pickup trucks. Thus, the distributional effect of these random

7 parameters is affected, and in both cases, the percentage of trips exhibiting unsafe lane changes

8 decreases. In contrast, greater number of vehicles in the household is found to increase the mean

9 of the random parameter relating to drivers with high trip frequency. Thus, in cases of households

10 with greater number of vehicles, drivers with high trip frequency are more likely to perform unsafe

11 lane changes. 
1 Table 4. Estimation Results of the Grouped Random Parameters Ordered Probit Model with 2 Heterogeneity in Means for Unsafe Lane Changes

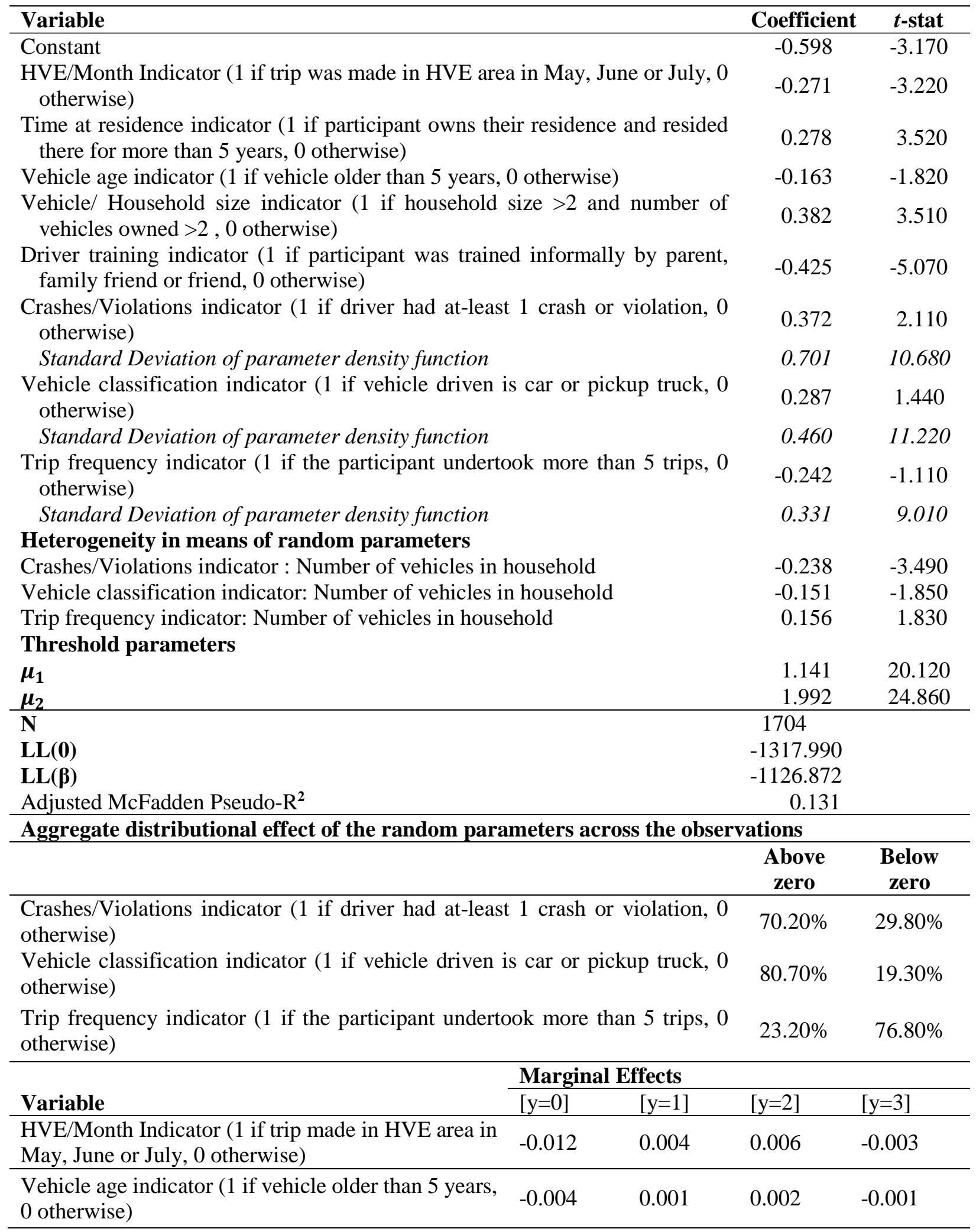




\begin{tabular}{|c|c|c|c|c|}
\hline \multirow[b]{2}{*}{ Variable } & \multicolumn{4}{|c|}{ Marginal Effects } \\
\hline & {$[y=0]$} & {$[\mathrm{y}=1]$} & {$[y=2]$} & {$[y=3]$} \\
\hline $\begin{array}{l}\text { Vehicle/ Household size indicator (1 If household } \\
\text { size }>2 \text { and number of vehicles owned }>2,0 \\
\text { otherwise) }\end{array}$ & -0.021 & 0.004 & 0.011 & -0.006 \\
\hline $\begin{array}{l}\text { Driver training indicator ( } 1 \text { if participant was trained } \\
\text { informally by parent, family friend or friend, } 0 \\
\text { otherwise) }\end{array}$ & -0.025 & 0.002 & 0.015 & -0.009 \\
\hline $\begin{array}{l}\text { Crashes/Violations indicator ( } 1 \text { if driver had at-least } \\
1 \text { crash or violation, } 0 \text { otherwise) }\end{array}$ & -0.051 & 0.025 & 0.018 & -0.008 \\
\hline $\begin{array}{l}\text { Vehicle classification indicator ( } 1 \text { if vehicle driven is } \\
\text { car or pickup truck, } 0 \text { otherwise) }\end{array}$ & -0.023 & 0.010 & 0.009 & -0.004 \\
\hline $\begin{array}{l}\text { Trip frequency indicator ( } 1 \text { if the participant } \\
\text { undertook more than } 5 \text { trips, } 0 \text { otherwise })\end{array}$ & -0.006 & -0.002 & 0.005 & -0.003 \\
\hline \multicolumn{5}{|c|}{$\begin{array}{l}\text { Diagonal and off-diagonal elements of the } \Gamma \text { matrix [t-stats in brackets], and correlation } \\
\text { coefficients (in parentheses) for the correlated random parameters }\end{array}$} \\
\hline & $\begin{array}{l}\text { Month/ } \\
(1 \text { if } \\
\text { after } 6 t \\
\text { HVE } \\
\text { area, } 0\end{array}$ & $\begin{array}{l}\text { indicat } \\
\text { was ma } \\
\text { ay } 2012 \\
\text { ementati } \\
\text { wise) }\end{array}$ & \multicolumn{2}{|c|}{$\begin{array}{l}\text { Vehicle classification } \\
\text { indicator ( } 1 \text { if vehicle } \\
\text { driven is car or pickup } \\
\text { truck, } 0 \text { otherwise) }\end{array}$} \\
\hline $\begin{array}{l}\text { Month/HVE indicator ( } 1 \text { if trip was made after 6th } \\
\text { May } 2012 \text { in HVE implementation area, } 0 \text { otherwise) }\end{array}$ & 1.5 & $\begin{array}{l}{[2.17]} \\
00)\end{array}$ & \multicolumn{2}{|c|}{ 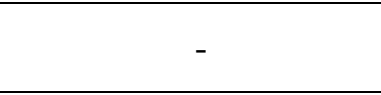 } \\
\hline $\begin{array}{l}\text { Vehicle classification indicator ( } 1 \text { if vehicle driven is } \\
\text { car or pickup truck, } 0 \text { otherwise) }\end{array}$ & 0.67 & $\begin{array}{l}4.450] \\
78)\end{array}$ & \multicolumn{2}{|c|}{$\begin{array}{l}0.7278[4.930] \\
(1.000)\end{array}$} \\
\hline
\end{tabular}


Table 5 provides the estimation results along with the (pseudo-) elasticities of the correlated

2 grouped random parameters binary logit model for 'other' aggressive driving behavior types.

3 Turning to estimation results, $67.2 \%$ of trips conducted after the first week of May 2012 in areas

4 of HVE implementation are less likely to exhibit any type of 'other' aggressive driving behaviors;

5 the opposite has been observed for the remaining 32.8\% of trips. This variable represents the core

6 period of HVE implementation, during which, the vast majority of drivers are aware of the

7 enforcement program; it should be noted that in the early period of implementation (e.g., in the

8 first few weeks), some drivers may not be informed that the high-visibility enforcement takes 9 place.

Table 5 shows that positive correlation (coefficient is equal to 0.678) may exist between 11 systematically varying unobserved factors captured by the two random parameters (HVE 12 implementation and month indicator; vehicle classification indicator). The positive value of the 13 correlation coefficient indicates that the interaction of the unobserved effects has consistent effect 14 (either positive or negative) on the probability of occurrence of 'other' aggressive driving 15 behaviors. This could be capturing unobserved habitual driving patterns that may vary across the 16 specific vehicle types (car or pickup truck).

Higher average speeding throughout the trip was found to increase the likelihood of 18 occurrence of such behavioral types, possibly capturing drivers’ consistent propensity to various 19 patterns of aggressive driving. Moreover, the type of vehicle (passenger car or pick-up trucks) is 20 found to have variable effect on the likelihood of occurrence across the trips. Specifically, the 
1 variable increases the likelihood of occurrence of 'other' aggressive driving behavior types for

2 almost half of the trips, and decreases it for the other half of trips.

As far as the driver-specific characteristics are concerned, any type of 'other' aggressive

4 driving behaviors is more likely (by 10.3\%) to occur in trips conducted by Hispanic or Latino

5 drivers. In addition, trips made by female drivers without full-time employment are less likely (by

$6-4.2 \%)$ to exhibit 'other' aggressive driving behavior types. This finding may be picking up the

7 effect of driving habits of this group of drivers, who are overall less likely to indulge in aggressive

8 driving (Shinar and Compton, 2004; Fountas et al., 2019). This group of drivers is also likely to

9 escort children in various activities (e.g., school, leisure, sports), as such, they may exercise greater

10 driving caution while conducting children-related trips. 
1 Table 5. Correlated Grouped Random Parameters Binary Logit Model for 'Other' Aggressive 2 Driving Behaviors

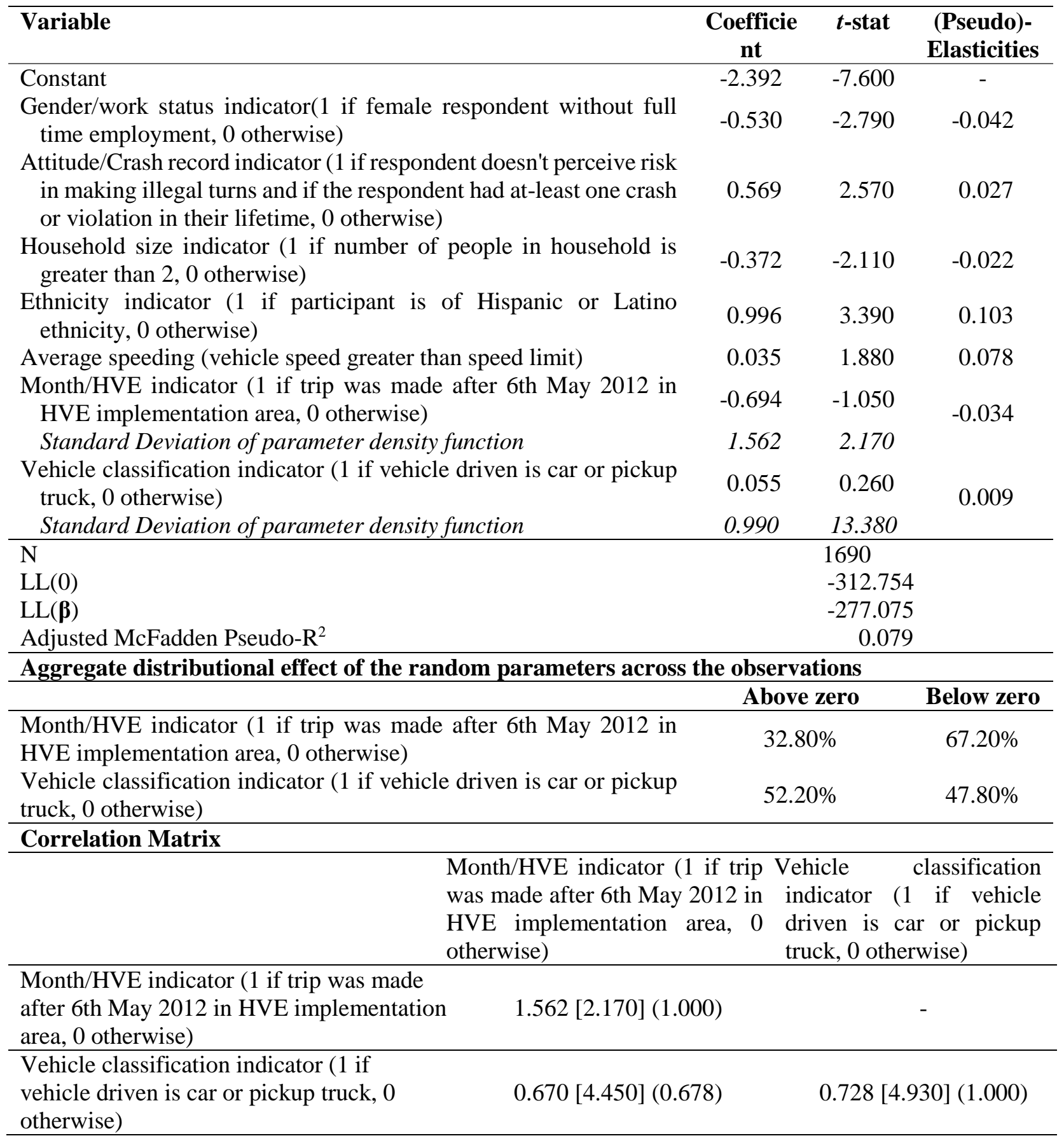




\section{SUMMARY AND CONCLUSION}

This paper provides a comprehensive investigation of the effect of HVE implementation on speeding, tailgating, unsafe lane changes and 'other' aggressive driving behavior types controlling, at the same time, for the effect of other influential driver-, trip-, weather- and vehicle-specific characteristics. The SHRP2 Naturalistic Driving Study data were analyzed to identify various behavioral traits of drivers before, during and after the HVE implementation in two sites in Erie County, NY. The development of unique - to the authors' knowledge - scaled speeding and tailgating metrics can provide a more robust assessment of the various levels of speeding and tailgating behavior, since the determinants of each separate level of speeding and tailgating behavior can be directly identified.

In term of speeding and tailgating, the HVE programs are found to have an indirect effect on driving behavior. The results of the statistical analysis showed that the awareness of HVE implementation decreases the metrics of speeding and tailgating for traversals across the control areas. In terms of unsafe lane changes, the HVE programs are observed to have a more direct and pronounced effect on driving behavior. The results show that HVEs have the potential to reduce the likelihood of unsafe lane changes, not only during the implementation period but also during the post-implementation period. At the same time, HVEs are found to reduce the likelihood of other aggressive driving behavior types (such as red light / stop sign violations and failure to yield right-of-way) for the vast majority of drivers.

This study proposes a comprehensive evaluation framework of the effectiveness of HVE programs in addressing various aspects of aggressive driving behavior. This framework can be effectively used for the investigation of similar safety countermeasures, while the empirical findings of the analysis can be leveraged for the development of "soft" safety countermeasures. 
1 Specifically, as highlighted by the study findings, the post-licensure driver training is effective in

2 curbing aggressive driving tendencies, and specifically speeding behavior. In this context, new

3 training or awareness raising campaigns could be developed and targeted at groups of driving

4 population with persistent, yet aggressive driving patterns. For example, such groups may include

5 drivers prone to traffic violations or drivers with high driving self-efficacy, who were found not to

6 be significantly affected by the enforcement programs in terms of modifying their behavioral 7 patterns.

ACKNOWLEDGEMENTS

10 The research work was supported by the Federal Highway Administration (FHWA). The contents

11 of this paper reflect the views of the authors, who are responsible for the facts and the accuracy of

12 the data presented herein. The contents do not necessarily reflect the official views or policies of 13 any agency, nor do the contents constitute a standard, specification, or regulation.

\section{REFERENCES}

Anastasopoulos, P.Ch., Mannering, F.L., 2009. A note on modeling vehicle-accident frequencies with random parameter count models. Accident Analysis and Prevention, 41(1), 153-159.

Anastasopoulos, P.Ch., Mannering, F.L., 2011. An empirical assessment of fixed and random parameter logit models using crash- and non-crash-specific injury data. Accident Analysis and Prevention, 43(3), 1140-1147.

Anastasopoulos, P.Ch., Mannering, F.L., Shankar, V., Haddock, J., 2012. A study of factors affecting highway accident rates using the random-parameters tobit model. Accident Analysis and Prevention, 45, 628-633. 
1 Anastasopoulos, P.Ch., Mannering, F.L., 2016. The effect of speed limits on drivers' speed choice: A random parameters seemingly unrelated equations approach. Analytic Methods in Accident Research, 10, 1-11.

Anastasopoulos, P.Ch., Sarwar, T., Shankar, V., 2016. Safety-oriented pavement performance thresholds: Accounting for unobserved heterogeneity in a multi-objective optimization and goal programming approach. Analytic Methods in Accident Research, 12, 35-47.

Bagdade, J., Nabors, D, McGee, H., Miller, R., Retting, R., 2012. Speed Management: A Manual for Local Rural Road Owners. FHWA-SA-12-027 Technical Report, pp. 62.

Behnood, A., Mannering, F.L., 2017a. Determinants of bicyclist injury severities in bicyclevehicle crashes: a random parameters approach with heterogeneity in means and variances. Analytic methods in accident research, 16, 35-47.

Behnood, A., Mannering, F.L., 2017b. The effect of passengers on driver-injury severities in single-vehicle crashes: A random parameters heterogeneity-in-means approach. Analytic methods in accident research, 14, 41-53.

Bhat, C., 2003. Simulation estimation of mixed discrete choice models using randomized and scrambled Halton sequences. Transportation Research Part B, 37(1), 837-855.

Chen, C., Zhang, G., Huang, H., Wang, J., Tarefder, R.A., 2016. Examining driver injury severity outcomes in rural non-interstate roadway crashes using a hierarchical ordered logit model. Accident Analysis and Prevention, 96, 79-87.

Cunningham, C., Schroeder, B., Vaughan, C., Hughes, R., 2011. Is Ticketing Aggressive Cars and Trucks Effective in Changing Driver Behavior? Evidence from North Carolina. Transportation Research Record: Journal of the Transportation Research Board, 2265, 100-108. 
1 Eker, U., Ahmed, S.S., Fountas, G., Anastasopoulos, P.Ch., 2019. An exploratory investigation of public perceptions towards safety and security from the future use of flying cars in the United States. Analytic Methods in Accident Research, 100103.

Ellison-Potter, P., Bell, P., Deffenbacher, J., 2001. The effects of trait driving anger, anonymity, and aggressive stimuli on aggressive driving behavior. Journal of Applied Social Psychology, 31(2), 431-443.

Feng, F., Bao, S., Sayer, J. R., Flannagan, C., Manser, M., Wunderlich, R., 2017. Can vehicle longitudinal jerk be used to identify aggressive drivers? An examination using naturalistic driving data. Accident Analysis \& Prevention, 104, 125-136.

Files, T., 2013. Analyzing Driving behavior: Using Data from the SHRP 2 Naturalistic Driving Study

Fountas, G., Anastasopoulos, P. Ch., 2017. A random thresholds random parameters hierarchical ordered probit analysis of highway accident injury-severities. Analytic methods in accident research, 15, 1-16.

Fountas, G., Sarwar, M.T., Anastasopoulos, P.C., Blatt, A., Majka, K., 2018a. Analysis of stationary and dynamic factors affecting highway accident occurrence: a dynamic correlated grouped random parameters binary logit approach. Accident Analysis \& Prevention, 113, 330-340.

Fountas, G., Anastasopoulos, P.Ch., Mannering, F.L., 2018b. Analysis of vehicle accident-injury severities: a comparison of segment-versus accident-based latent class ordered probit models with class-probability functions. Analytic Methods in Accident Research, 18, 1532. 
1 Fountas, G., Anastasopoulos, P.Ch., Abdel-Aty, M., 2018c. Analysis of accident injury-severities using a correlated random parameters ordered probit approach with time variant covariates. Analytic Methods in Accident Research, 18, 57-68.

Fountas, G., Anastasopoulos, P.Ch., 2018. Analysis of accident injury-severity outcomes: The zero-inflated hierarchical ordered probit model with correlated disturbances. Analytic Methods in Accident Research, 20, 30-45.

Fountas, G., Pantangi, S.S., Hulme, K.F., Anastasopoulos, P.Ch., 2019. The effects of driver fatigue, gender, and distracted driving on perceived and observed aggressive driving behavior: A correlated grouped random parameters bivariate probit approach. Analytic Methods in Accident Research, 100091.

Fountas, G., Rye, T., 2019. A note on accounting for underlying injury-severity states in statistical modeling of injury accident data. Procedia Computer Science, 151, 202-209.

Greene, W.H., 2012. Econometric Analysis. Prentice Hall. ISBN-13: 978-0131395381

Habtemichael, F.G., de Picado Santos, L., 2014. Crash risk evaluation of aggressive driving on motorways: Microscopic traffic simulation approach. Transportation research part F: traffic psychology and behaviour, 23, 101-112.

Halton, J., 1960. On the efficiency of certain quasi-random sequences of points in evaluating multi-dimensional integrals. Numerische Mathematik, 2, 84-90.

Jordan, G.A., Anastasopoulos, P.Ch., Peeta, S., Somenahalli, S., Rogerson, P.A., 2019. Identifying elderly travel time disparities using a correlated grouped random parameters hazard-based duration approach. Research in Transportation Business \& Management, 100369. 
1 Jovanis, P., Aguero-Valverde, J., Wu, K.F., Shankar, V., 2011. Analysis of naturalistic driving event data: Omitted-variable bias and multilevel modeling approaches. Transportation Research Record: Journal of the Transportation Research Board, 2236, 49-57.

Lee, J., Abdel-Aty, M., Cai, Q., Wang, L., 2018. Effects of emergency medical services times on traffic injury severity: A random effects ordered probit approach. Traffic injury prevention, 19(6), 577-581.

Lee, J.Y., Lee, J.D., Bärgman, J., Lee, J., Reimer, B., 2018. How safe is tuning a radio?: using the radio tuning task as a benchmark for distracted driving. Accident Analysis \& Prevention, 110, 29-37.

Mannering, F. L., Shankar, V., Bhat, C. R., 2016. Unobserved heterogeneity and the statistical analysis of highway accident data. Analytic methods in accident research, 11, 1-16.

Meng, F., Wong, S.C., Yan, W., Li, Y.C., Yang, L., 2019. Temporal patterns of driving fatigue and driving performance among male taxi drivers in Hong Kong: A driving simulator approach. Accident Analysis \& Prevention, 125, 7-13.

National Center for Statistics and Analysis, 2016, August. 2015 motor vehicle crashes: Overview. (Traffic Safety Facts Research Note. Report No. DOT HS 812 318). Washington, DC: National Highway Traffic Safety Administration

National Center for Statistics and Analysis, 2017, May. Speeding: 2015 data (Traffic Safety Facts. DOT HS 812 409). Washington, DC: National Highway Traffic Safety Administration.

NCHRP, 2003. Volume 1: A Guide for Addressing Aggressive-Driving Collisions. NCHRP, NCHRP Report 500, Project G17-18(3), TRB.

Paleti R, Eluru N, Bhat CR., 2010. Examining the influence of aggressive driving behavior on driver injury severity in traffic crashes. Accident Analysis and Prevention, 42, 1839-1854. 
1 Pantangi, S.S., Fountas, G., Sarwar, M.T., Anastasopoulos, P.C., Blatt, A., Majka, K., Pierowicz, J., Mohan, S.B., 2019. A preliminary investigation of the effectiveness of high visibility enforcement programs using naturalistic driving study data: A grouped random parameters approach. Analytic Methods in Accident Research, 21, 1-12.

Pierowicz, J., Anastasopoulos. P.C., Blatt, A., Sarwar, M.T., Majka, K., Sarvani, S.P., 2016. Research Utilizing the SHRP2 Safety Data to Support Highway Safety-The Development of New Insights into Driver Behavior to Improve High Visibility Safety Enforcement Programs (HVE). Technical Report for FHWA BAA, Project Number DTFH61-16-C0004.

Russo, B., Savolainen, P., Schneider, W., Anastasopoulos, P., 2014. Comparison of factors affecting injury severity in angle collisions by fault status using a random parameters bivariate ordered probit model. Analytic Methods in Accident Research, 2, 21-29.

Sarwar, M.T., Anastasopoulos, P.Ch., 2016. Three-stage least squares analysis of postrehabilitation pavement performance. Transportation Research Record: Journal of the Transportation Research Board, 2589, 97-109.

Sarwar, M.T., Fountas, G., Bentley, C., Anastasopoulos, P.C., Blatt, A., Pierowicz, J., Majka, K., Limoges, R., 2017a. Preliminary Investigation of the Effectiveness of High-Visibility Crosswalks on Pedestrian Safety Using Crash Surrogates. Transportation Research Record: Journal of the Transportation Research Board, 2659, 182-191.

Sarwar, T., Anastasopoulos, P.Ch., Golshani, N., Hulme, K., 2017b. Grouped random parameters bivariate probit analysis of perceived and observed aggressive driving behavior: A driving simulation study. Analytic Methods in Accident Research, 13, 52-64. 
1 Sarwar, T., Fountas, G., Anastasopoulos, P.Ch., 2017c. Simultaneous estimation of discrete outcome and continuous variable equations: A random effects modeling approach with unrestricted instruments. Analytic Methods in Accident Research, 16, 23-34.

Seraneeprakarn, P., Huang, S., Shankar, V., Mannering, F., Venkataraman, N., Milton, J., 2017. Occupant injury severities in hybrid-vehicle involved crashes: A random parameters approach with heterogeneity in means and variances. Analytic Methods in Accident Research, 15, 41-55.

Shinar, D., Compton, R., 2004. Aggressive driving: an observational study of driver, vehicle, and situational variables. Accident Analysis \& Prevention, 36(3), 429-437.

Simons-Morton, Bruce G., Ouimet, M. C., Zhang, Z., Klauer, S. E., Lee, S. E., Wang, J., Dingus, T. A., 2011. The effect of passengers and risk-taking friends on risky driving and Crashes/Near crashes among novice teenagers. Journal of Adolescent Health, 49(6), 587593. doi:10.1016/j.jadohealth.2011.02.009

Song, M., Wang, J.H., 2010. Studying the tailgating issues and exploring potential treatment. Journal of the transportation research forum, 49 (1424-2016-117925), 69-86.

Stuster, J. Aggressive Driving Enforcement: Evaluation of Two Demonstration Programs., 2004. DOT HS 809 707, Washington, D.C.: National Highway Traffic Safety Administration.

Tarko AP, Anastasopoulos P.Ch., Zuriaga AMP, 2011. Can Education and Enforcement Affect Behavior of Car and Truck Drivers on Urban Freeways? International Conference on Road Safety and Simulation.

Tasca, L., 2000. A review of the literature on aggressive driving research. Ontario, Canada: Ontario Advisory Group on Safe Driving Secretariat, Road User Safety Branch, Ontario Ministry of Transportation. 
1 Train, K., 2003. Discrete choice methods with simulation. Cambridge University Press, 2 Cambridge, United Kingdom.

3 Wang, B., Hallmark, S., Savolainen, P., Dong, J., 2018. Examining vehicle operating speeds on 4 rural two-lane curves using naturalistic driving data. Accident Analysis \& Prevention, 118, 5 236-243.

6 Wang, X., Yang, M., Hurwitz, D., 2019. Analysis of cut-in behavior based on naturalistic driving

8 Washington SP, Karlaftis MG, Mannering FL., 2011. Statistical and Econometric Methods for 9 Transportation Data Analysis. Chapman \& Hall/CRC.

10 Wu, K.F., Jovanis, P.P., 2012. Crashes and crash-surrogate events: Exploratory modeling with 11 naturalistic driving data. Accident Analysis and Prevention, 45, 507-516.

12 Yang, L., Ma, R., Zhang, H.M., Guan, W., Jiang, S., 2018. Driving behavior recognition using 13 EEG data from a simulated car-following experiment. Accident Analysis \& Prevention, 116, 30-40.

15 Yu, R., Xiong, Y., Abdel-Aty, M., 2015. A correlated random parameter approach to investigate 16 the effects of weather conditions on crash risk for a mountainous freeway. Transportation research part C: emerging technologies, 50, 68-77. 